\title{
Metabolic Basis for Disorders of Purine Nucleotide Degradation
}

\author{
Irving $H$. Fox
}

\begin{abstract}
Purine nucleotide degradation refers to a regulated series of reactions by which human purine ribonucleotides and deoxyribonucleotides are degraded to uric acid in humans. Two major types of disorders accur in this pathway. A block of degradation occurs with syndromes involving immune deficiency. myopethy or renal calculi. Increased degradation of nucleotides occurs with syndromes characterized by hyperuricemia and gout, renal calculi, anemia or acute hypoxia. Management of disorders of purine nucleotide degradation is dependent upon modifying the specific molecular pathology underlying each disease state.
\end{abstract}

$\mathbf{A}^{\mathrm{N}}$ N EXPLOSION of information about disorders of purine nucleotide degradation in humans has occurred during the past $8 \mathrm{yr}$. The discovery of seven new enzyme abnormalities associated with specific clinical syndromes and the intensive research to elucidate the underlying molecular pathology have provided the basis for the major advances. New concepts have related tissue ATP levels and their depletion by hypoxic or metabolic mechanisms to common clinical abnormalities.

Disorders of purine nucleotide degradation now encompass a range of previously unsuspected disease associations. Immunodeficiency, myopathy, renal calculi, hyperuricemia and gout, ancmia, central nervous system dysfunction and tissue hypoxia occur with abnormalities of this biochemical pathway. In this review, diseases of purine nucleotide degradation will be described. Two major types of disorders occur; blocks of purine nucleotide degradation and increased activity of this pathway. The metabolic basis underlying altered regulation of purine nucleotide degradation to uric acid in these diseases will be described as it is understood at the present time focusing on the more recent advances.

\section{REGULATION OF PURINE NUCLEOTIDE DEGRADATION}

Purine nucleoside monophosphate derivatives are degraded to uric acid in humans by a final common pathway (Fig. 1). Complex regulation of this pathway is evident from experiments which increase the degra-

From the Human Purine Research Center, Departments of Internal Medicine and Biological Chemistry, Clinical Research Center, University of Michigan, Ann Arbor, Michigan.

Received for publication October 28,1980.

This work supported in part by USPHS grants AM 19674 and $5 M 01 R R 42$, and grants from the Michigan Heart Association and the Warner Lambert Company.

Address reprint requests to Dr. I. H. Fox, University Hospital, Clinical Research Center, W-4642 Main Hospital, Ann Arbor, Michigan 48109.

(c) 1981 by Grune \& Stratton, Inc.

0026-0495/81/3006-0017\$02.00/0 dation of purine nucleotides. Activation of nucleotide degradation to inosine and hypoxanthine occurs in ascites tumor cells following incubation with 2-deoxyglucose or glucose. ${ }^{1-4}$ There is rapid utilization of ATP during the phosphorylation of these compounds. The sudden diminution of intracellular ATP concentrations and the resulting elevation of AMP and IMP levels appear to be triggering factors for the activation of nucleotide degradation.

Experimental evidence in humans indicates that altered regulation of the pathway may accelerate the degradation of purine nucleotides. A model for activation of purine nucleotide degradation in humans is provided by the rapid infusion of fructose. In less than $60 \mathrm{~min}$ after intravenous fructose there is an increase of the serum urate concentration and an elevation of urinary uric acid, oxypurine (hypoxanthine and xanthine) and inosine excretion (Fig. 2). ${ }^{5-9}$ In human liver there is a depletion of total adenine nucleotides, predominantly ATP, and inorganic phosphate within $30 \mathrm{~min}$ of a fructose infusion. ${ }^{10}$ These observations suggest that the rapid phosphorylation of infused fructose by ATP leads to hepatic ATP degradation to the purine compounds measured in blood and urine. Vigorous muscular exercise in man causes a rise of the serum urate level and an elevation of plasma and urinary oxypurines. ${ }^{11-13}$ This may be related to an increase of uric acid synthesis from the degradation of muscle ATP during exercise, since there is a diminution of vastus lateralis muscle ATP concentrations. ${ }^{13}$ These observations are compatible with an activation of purine nucleotide degradation, initiated by a sudden decrease of intracellular ATP and inorganic phosphate concentrations during exercise.

\section{Dephosphorylation}

The dephosphorylation of nucleoside 5 -monophosphates (Fig. 1, reaction 1) is the first committed and irreversible reaction of purine nucleotide degradation. It has been proposed to be the major site of regulation of the pathway. ${ }^{14}$ Four distinctive subcellular types of 5 -nucleotidase have been recognized to hydrolyze 


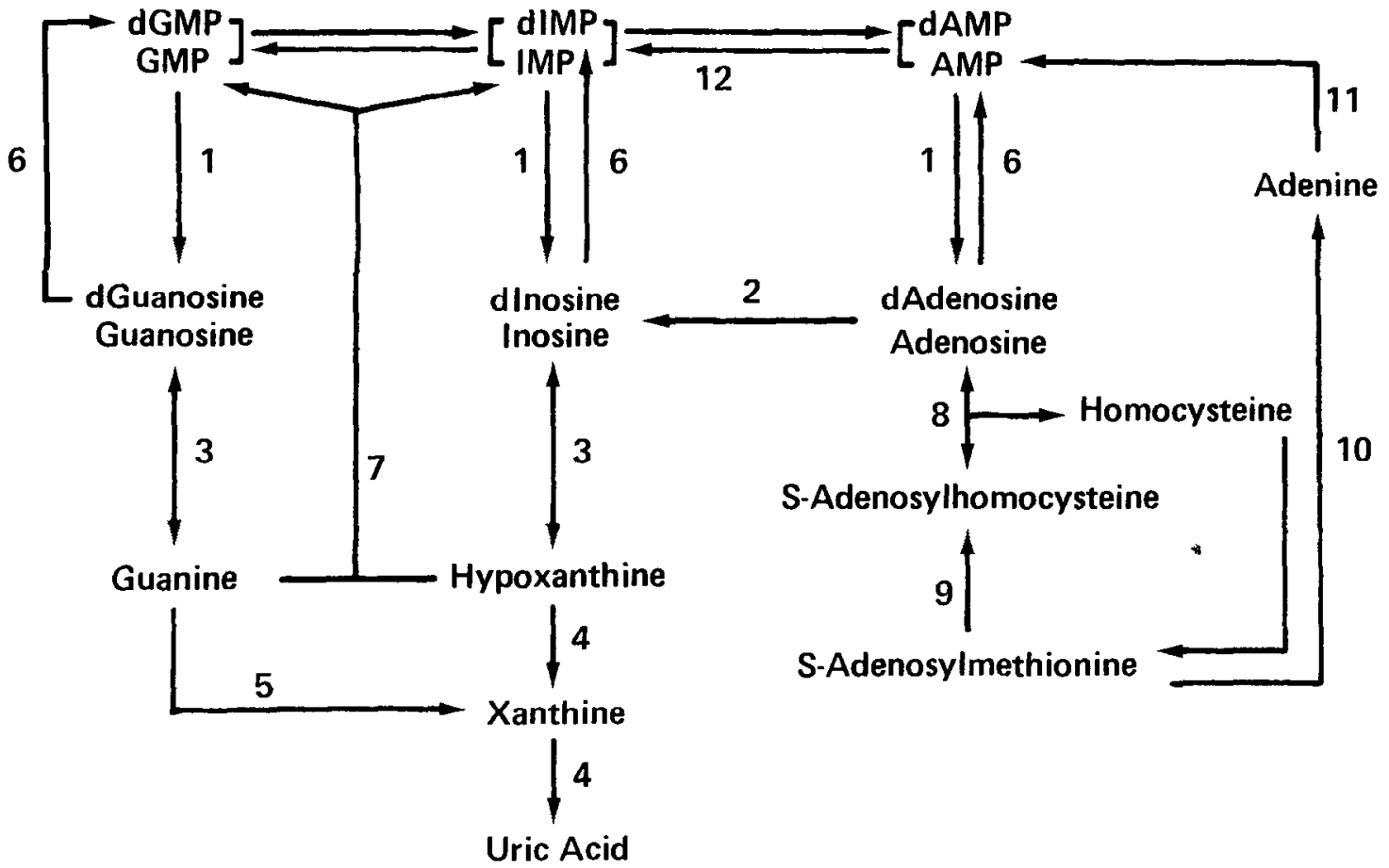

Fig. 1. Pathway of purine nucleotide degradation. Purine nucleoside monophosphate derivatives are degraded to uric acid in humans by a final common pathway. Nucleotides are dephosphorylated to form the nucleoside derivatives. Specific $5^{\prime}$-phosphomonoesterase (E.C.3.1.3.5) and non-specific phosphatases (E.C.3.1.3.2) hydrolyze AMP. IMP, GMP or their deoxynucleoside monophosphates to the nucleoside or deoxynucleoside derivatives (reaction 1). AMP is deaminated to IMP by AMP deaminase (E.C.3.5.4.6, reaction 12). Inosine, deoxyinosine, deoxyguanosine, and guanosine are converted to purine bases and ribose-1-phosphate or deoxyribose-1-phosphate by purine nucleoside phosphorylase (E.C.2.4.2.1. reaction 3). Adenosine and deoxyadenosine are deaminated to inosine and deoxyinosine by adenosine deaminase (E.C.3.5.4.6, reaction 2). Guanine is deaminated to xanthine by guanine deaminase (E.C.3.5.4.3, reaction 5). Hypoxanthine and xanthine are oxidized to uric acid by xanthine oxidase (E.C.1.2.3.2, reaction 4) located primarily in the liver and jejunem of mammals. These pathways are interrupted by reactions which allow the resynthesis of nucleotides. Nucleoside kineses catalyze the conversion of adenosine to AMP, deoxyadenosine to dAMP, deoxyinosine to diMP and deoxyguanosine to dGMP (reaction 6). Hypoxanthine-guanine phosphoribosyltransferase (E.C.2.4.2.8, reaction 7) converts hypoxanthine or guanine to IMP or GMP. Adenine phosphoribosyltransferase (E.C.2.4.2.7, reaction 11) catalyzes the formation of AMP from adenine. The precursor substrates of the final common pathway of purine nucleotide degradetion are formed from the digestion of dietary nucleoprotein, the degradation of nucleic acids to nucleoside monophosphates and the formation of nucleotides by de novo purine synthesis and the purine salvage pathways. In addition, S-adenosylhomocysteine is degraded to adenosine and homocysteine by S-adenosylhomocysteine hydrolase (E.C.3.3.1.1, reaction 8) in an essential step of S-adenosylmethionine mediated methylation reactions (reaction 9). S-adenosyimethionine may also be decarboxylated to enter polyamine metabolism (reaction 10). Degradation of deoxyribonucleotides follows a similar pattern as indicated. However, dAMP may be converted to dIMP at only 6\% of the $V_{\max }$ of AMP (232) (reaction 12), while dIMP may be converted to dGMP or dAMP at virtually the same $V_{\max }$ as IMP (233-236). dGMP may be converted back to dIMP at about 1\% of the $V_{\max }$ of GMP (237). The dephosphorylation of deoxynucleotides, the deamination of deoxyedenosine and the phosphorolysis of deoxyinosine or deoxyguanosine are all similer to the reactions of the ribosyl derivatives (Reviewed in Reference 14). GMP, guanosine 5'-monophosphate; dGMP. deoxyguanosine 5'-monophosphate; IMP, inosine 5'-monophosphate; dIMP, deoxyinosine 5'-monophosphate; AMP, adenosine 5'monophosphate: dAMP, deoxyadenosine $5^{\prime}$-monophosphate.

purine nucleoside 5 -monophosphates. ${ }^{15}$ These include enzymes in plasma membrane, microsomes, lysosomal membrane, and cytoplasm. The plasma membrane 5 -nucleotidase has been the focus of many studies although its function is not clear. The enzyme faces the outer surface of the plasma membrane. ${ }^{16-22}$ Substrate specificity is localized to $5^{\prime}$-monophosphate compounds. The enzyme is inhibited by nucleoside diphosphate and triphosphate derivatives and concanavalin A. ${ }^{17,20,21,23}$ Extracellular nucleoside 5'-monophosphates are degraded to their nucleoside derivatives in preparation for uptake, since the negatively charged nucleotides are not transported across the cell membrane under usual circumstances. A vectorial transport system for the adenosine component of AMP into rat myocardial cells has been suggested during perfusion with AMP. ${ }^{24}$

Plasma membrane $5^{\prime}$-nucleotidase may be an important site for the regulation of purine nucleotide degradation, since activation of this pathway occurs with a depletion of ATP, an inhibitor of this enzyme, and an accumulation of IMP and AMP, substrates for this enzyme. However, recent observations indicate that plasma membrane 5 '-nucleotidase may not influence intracellular nucleotide degradation. ${ }^{25}$ A 5 'nucleotidase that occurs in the supernatant fraction of 


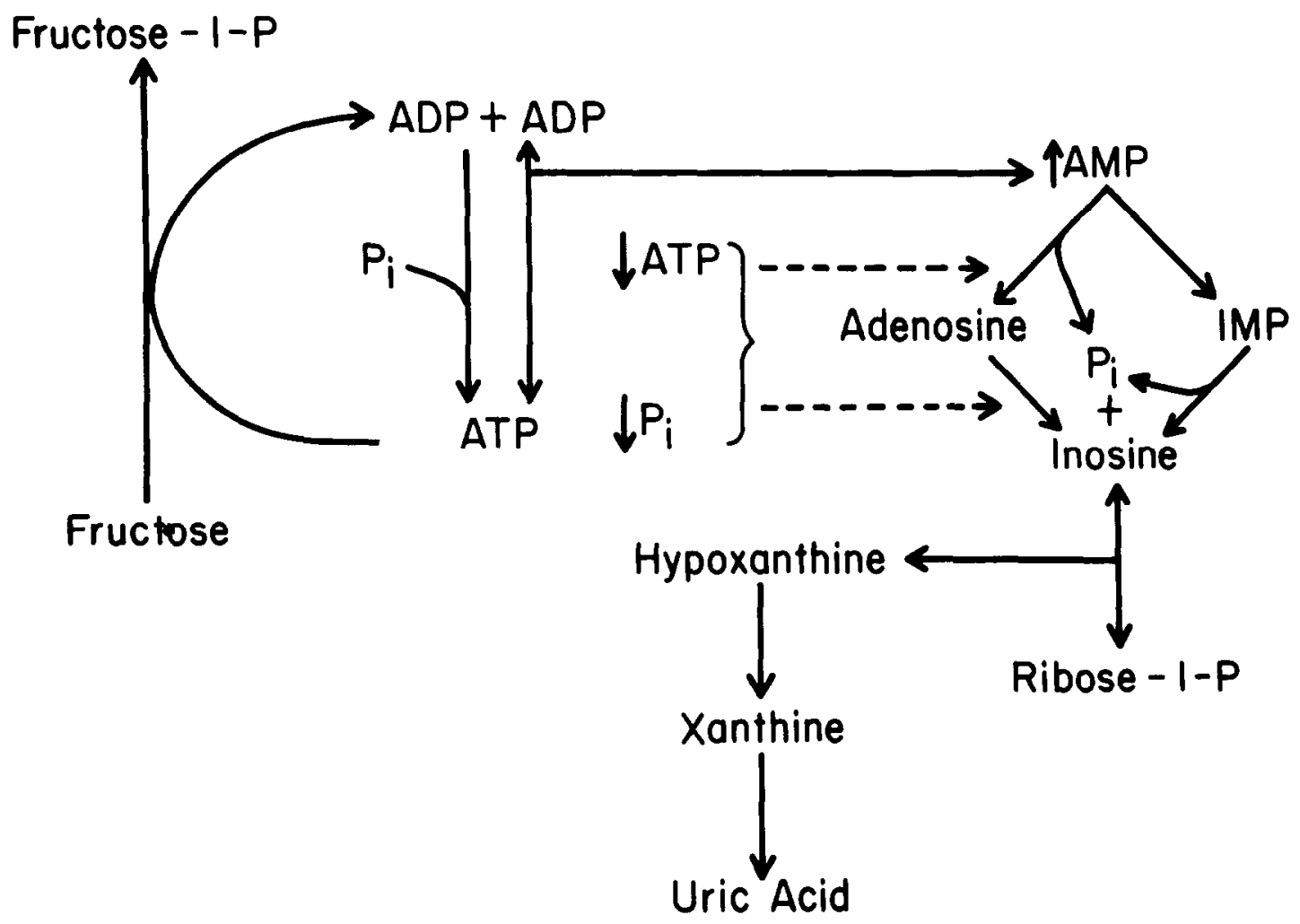

Fig. 2. Mechanism of fructose-induced purine nucleotide degradation. Fructose triggers the rapid breakdown of purine nucleotides to uric acid in the liver. The phosphorylation of fructose to fructose-1-phosphate causes ATP to be degraded to ADP. Fructose-1-P tends to accumulate and thus traps inorganic phosphate. ADP is converted back to ATP by the mitochondrial electron transport system or glycolysis, which use inorganic phosphate, or by adenylate kinase. The latter reaction also forms AMP. The net result is a diminution of intracellular ATP and inorganic phosphate and buildup of AMP. The elevated AMP concentrations also lead to increased IMP concentration. Dephosphorylation of $5^{\prime}$-nucleotidase is triggered. If AMP and IMP concentrations are high enough, then non-specific phosphatase can be activated. Once dephosphorylation is activated, there is a cascade of nucleotide degradation through the catabolic pathways leading to increased synthesis of uric acid and accounting for hyperuricemia and the elevated urinary excretion of inosine. hypoxanthine, xanthine and uric acid. Inhibition is indicated by dotted lines. Vertical arrows beside ATP, Pi and AMP show changes caused by the fructose infusion (From Fox, Reference 14).

chicken liver ${ }^{26,27}$ and rat liver ${ }^{28-30}$ may catalyze cytoplasmic nucleoside 5 -monophosphate dephosphorylation. This enzyme preferentially hydrolyzes IMP and GMP, is activated by ATP and ADP and is inhibited by inorganic phosphate. Although it is highly likely that important regulation of purine nucleotide degradation occurs at the level of dephosphorylation, the nature of the regulation at this reaction remains to be clearly delineated.

\section{AMP Deamination}

The deamination of AMP (Fig. 1, reaction 12) has been proposed as the rate-limiting reaction in adenine nucleotide degradation instead of $5^{\prime}$-nucleotidase. ${ }^{31}$ Inorganic phosphate and GTP at physiological concentrations inhibit AMP deaminase by $95 \%{ }^{32}$ and are decreased in concentration during fructose infusion. This is proposed to activate the enzyme and lead to adenine nucleotide degradation. ${ }^{32}$ However, in contrast to this proposal, under physiological conditions or in intact cells a rise in AMP, ADP and $\mathrm{H}^{+}$ concentrations is the major factor increasing the activity of AMP deaminase, ${ }^{33}$ while altered ATP, GTP and GDP levels do not change the activity. ${ }^{34-36}$ Therefore, it remains unclear whether AMP deamination is limiting for purine nucleotide degradation. The complicated regulation of this enzyme, its important location in the pathway, and the fact that adenine nucleotides constitute the majority of free cellular nucleotides make this a serious consideration.

AMP deaminase has an additional important role as a component of the purine nucleotide cycle in skeletal muscle. ${ }^{37}$ This reaction sequence causes the relcase of ammonia during muscle contraction and the resynthesis of AMP from IMP. The sequence may be important to energy metabolism and ATP synthesis during muscle contraction.

\section{Reutilization}

The major regulatory mechanism of purine nucleotide degradation after dephosphorylation may be reutilization pathways. Guanine and hypoxanthine are 
resynthesized to their respective nucleotides by hypoxanthine-guanine phosphoribosyltransferase (Fig. 1, reaction 7). This enzyme is regulated by the availability of intracellular phosphoribosylpyrophosphate and product inhibition. The importance of this reaction is illustrated by its deficiency, which leads to excessive synthesis of uric acid in part, from an inability to reutilize the substrate purine bases. ${ }^{38}$

Adenosine, deoxyadenosine, deoxyinosine and deoxyguanosine can be phosphorylated to their respective nucleoside $5^{\prime}$-monophosphates by kinase enzymes (Fig. 1, reactions 6). Adenosine phosphorylation may be important in maintaining normal intracellular ATP concentrations. In erythrocytes with increased adenosine deaminase activity there is a decrease in ATP concentrations and hemolytic anemia. ${ }^{39}$ The removal of adenosine by its deamination in this disease suggests that erythrocytes require adenosine phosphorylation to synthesize normal quantities of ATP. Adenosine kinase is regulated by adenosine, ATP and $\mathrm{Mg}$ concentrations, and is inhibited by ADP, AMP, deoxyadenosine and $\mathrm{S}$-adenosylhomocysteine. ${ }^{40}$ Therefore, alterations in kinase activity may occur when adenosine or deoxyadenosine accumulates. Attention has been focused upon these reactions in adenosine deaminase deficiency, where both adenosine and deoxyadenosine accumulate in affected patients. Although there is evidence to suggest that adenosine and deoxyadenosine are phosphorylated by the same enzyme, some experiments demonstrate the existence of a distinct enzyme for deoxyadenosine phosphorylation $^{4145}$ possibly associated with deoxycytidine kinase activity. ${ }^{45}$ Observations with highly purified adenosine kinase suggest that adenosine kinase and deoxyadenosine kinase are distinct enzymes, with the former also having only a small amount of deoxyadenosine phosphorylating activity. ${ }^{44}$

\section{MEASUREMENT OF PURINE NUCLEOTIDE DEGRADATION}

The development of methods for the quantitation of purine nucleotide degradation in whole cells has lead to refined techniques to measure this pathway in humans.

\section{In Vitro Measurements}

The basis for the measurement of purine nucleotide degradation in cells is to alter the normal regulation of the pathway by causing a breakdown of ATP..$^{1-4}$ This initiates a cascade of purine nucleotide degradation with a flow of metabolites through the pathway to adenosine, inosine, and hypoxanthine. Deoxyglucose or inhibitors of the mitochondrial electron transport system and oxidative phosphorylation have been used to initiate degradation. The measurement of intracellular nucleotides and the quantitation of hypoxanthine, inosine, and adenosine allow an assessment of the activity of this pathway. A refinement of this technique is to prelabel the adenine nucleotide pool by incubation with radioactively labeled adenine. ${ }^{1.2}$ The stimulation of the breakdown of ATP under these conditions allows a clear documentation of the pathways of ATP degradation through the purine catabolic pathways.

\section{In Vivo Measurements}

Plasma and urinary purines. Measurements of plasma and urinary purines in man by standard spectrophotometric methods and more recently by high pressure liquid chromatography allow an assessment of disorders of the nucleotide degradation pathway. An increase in the serum urate concentration and in the urine uric acid excretion indicates increased activity of the purine nucleotide degradation pathway, since it demonstrates the increased synthesis of uric acid. On the other hand, a diminution of the serum urate concentration with very low urine uric acid excretion may indicate a block in uric acid synthesis. An accumulation of purine catabolic intermediates may localize such a block. For example, the excessive excretion of hypoxanthine and xanthine and hypouricemia may indicate a block at xanthine oxidase. Excretion of inosine, deoxyinosine, guanosine, and deoxyguanosine and hypouricemia may indicate a block at purine nucleoside phosphorylase (Fig. 1). Thus, simple measurements of plasma and urinary purines may provide a clue to an underlying disorder of purine nucleotide degradation. Other research methods are summarized below.

Fructose induced purine catabolism. A probe of the intactness and activity of the purine catabolic pathway may be carried out by the use of a fructose infusion. ${ }^{5} 10$ Fructose administered rapidly intravenously activates purine nucleotide degradation (Fig. 2). A block in the pathway will be reflected by a change of the normal pattern of urinary purine excretion following the fructose infusion. Alterations in the purine excretion following fructose infusion have been observed in deficiencies of purine nucleoside phosphorylase, xanthine oxidase and hypoxanthine-guanine phosphoribosyltransferase. ${ }^{46-48}$

Radioactive labeling of the adenine nucleotide pool. A radioactive isotope of adenine is administered intravenously to patients. This small quantity of adenine does not alter purine pool sizes and is incorporated into the adenine nucleotide pool. As the adenine nucleotide pool is turned over every day, there is a flow of radioactively labeled compounds through the purine 
nucleotide degradation pathway. The intermediates of purine nucleotide degradation are labeled separately from purines formed by the pathway of purine synthesis de novo. Some of these radioactively labeled purines will be excreted in the urine and can be easily measured. Block of the pathway or alteration of reutilization steps may change the quantity and pattern of urine radioactive purine excretion. This method has been used to demonstrate decreased hypoxanthine reutilization in Lesch-Nyhan Syndrome. ${ }^{48}$

Adenine labeling combined with fructose infusion. The two techniques described above may be combined for a sensitive probe to assess for alterations of the purine nuclentide degradation pathway in humans. The adenine nucleotide pool may be prelabeled three to four days prior to fructose infusion. Under these conditions the normal response to a fructose infusion is a 10-fold elevation of the urinary radioactivity over the baseline excretion (Edwards NL and Fox IH, unpublished results); the greatest increase of radioactivity is found in inosine and hypoxanthine in subjects with normal enzyme activity. ${ }^{48}$ Alteration in the amount or pattern of radioactivity excretion following the fructose infusion may indicate disorders of the purine nucleotide degradation pathway. Such an alteration has been discerned in hypoxanthine-guanine phosphoribosyltransferase deficien$\mathrm{cy},{ }^{48}$ but not in patients with lymphocyte plasma membrane 5 '-nucleotidase deficiency. ${ }^{49}$

\section{DISORDERS OF PURINE NUCLEOTIDE DEGRADATION}

Two major types of abnormalities of human purine nucleotide degradation occur; a block in the pathway and an increased activity of the pathway. Table 1 outlines a classification of disorders associated with alteration of purine nucleotide degradation. Blocks of purine nucleotide degradation may lead to an accumulation of the intermediates or their metabolites in human body fluids or cells. The accumulation of such intermediates may be toxic to certain cells and lead to clinical disorders such as immunodeficiency. An elevated rate of purine nucleotide degradation may lead to an increase in the end-products of the pathway. On the basis of the observations with fructose-induced purine nucleotide degradation which is triggered by massive ATP utilization (Fig. 2), an elevated rate of purine nucleotide degradation may be expressed by the following metabolic variables: an increase in the serum urate concentration and an elevation of urinary uric acid, inosine, and oxypurine excretion. ${ }^{50}$

\section{Blocks of Purine Nucleotide Degradation}

5 '-Nucleotidase deficiency of lymphocytes. The surface 5 '-phosphomonoesterase activity of peripheral
Table 1. Disorders of Purine Nucleotide Degradation

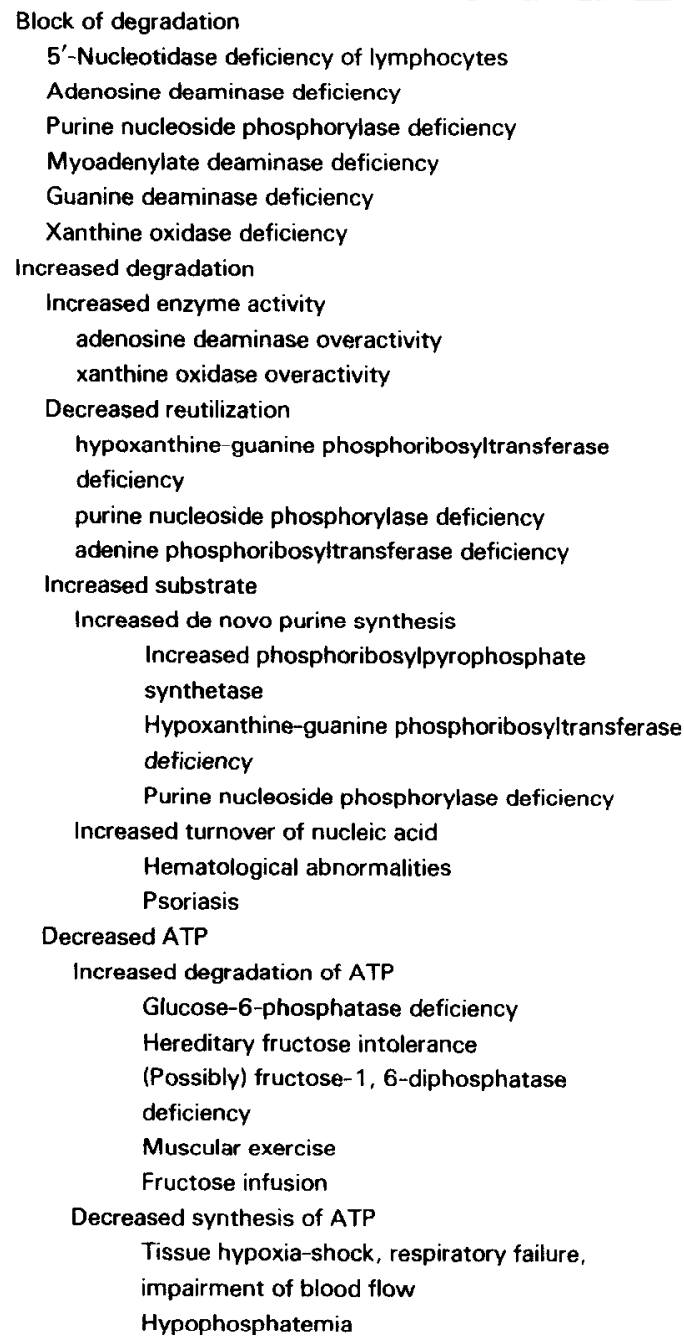

lymphocytes is decreased in certain patients with congenital agammaglobulinemia, common variable hypogammaglobulinemia, and selective $\operatorname{IgA}$ deficiency. ${ }^{49,51-53}$ The enzyme deficiency is related to a decrease in the number of 5 '-nucleotidase positive lymphocytes. ${ }^{54,55}$ The enzyme deficiency is measured in peripheral sheep erythrocyte rosette-forming lymphocytes $^{49.56-58}$ and in peripheral mononuclear cells depleted of monocytes ${ }^{56-59}$ and represents a block in the ability of these cells to degrade extracellular nucleoside 5'-monophosphates. The diminished activity of lymphocyte $5^{\prime}$-nucleotidase in these diseases appears to be related to decreased T-lymphocyte enzyme activity and decreased numbers of B-lymphocytes.

The question arises whether 5'-nucleotidase deficiency causes immune dysfunction or results from abnormal lymphocytes. The data suggest that abnormal lymphocytes are the basis for the enzyme deficien- 
cy. No structural alteration of the deficient enzyme has yet been demonstrated. ${ }^{52}$ The enzyme deficient patients have no evidence for a systemic disorder of purine nucleotide degradation and appear to have the deficiency only on lymphocytes. ${ }^{49}$ Erythrocyte and lymphocyte deoxynucleoside triphosphates are normal in $5^{\prime}$-nucleotidase deficiency. ${ }^{60}$ Finally, earlier stages of lymphocyte maturation may be characterized by lower values of 5 -nucleotidase, supporting the possibility that abnormal lymphocyte populations cause 5 '-nucleotidase deficiency. ${ }^{58,61}$

A deficiency of lymphocytc 5 -nuclcotidase has also been observed in chronic lymphocytic leukemia, acute lymphoblastic leukemia and transicntly in acute infectious mononucleosis. ${ }^{62-65}$

Adenosine deaminase deficiency. In 1972, the deficiency of adenosine deaminase was found in two unrelated patients with severe combined immunodeficiency disease. ${ }^{66}$ The enzyme deficiency accounts for about half of the patients with this syndrome and autosomal recessive inheritance. In $85 \%-90 \%$ of adenosine deaminase deficient patients there is severe lymphopenia, failure to thrive, and infections, diarrhea, malabsorption, and candidiasis with atrophic tonsils, adenoids, and thymus in the first few months of life. In 10\%-15\% of patients the disease may become evident later than 3-6 mo and immunoglobulin retention may occur. ${ }^{67,68} \mathrm{X}$-rays demonstrate evidence of osteoporosis, small or absent thymus gland, and chondro-osseous dysplasia at costochondral junctions, apophysis of iliac bones and vertebral bodies. There is a disorder of decreased platelet aggregation. ${ }^{69,70}$ Neurological abnormalities including nystagmus, head lag, spasticity, athetosis, and developmental delay occur in $10 \%-15 \%$ of patients. ${ }^{71}$

Biochemical abnormalities appear to account for the clinical syndrome. Elevated adenosine and deoxyadenosine concentrations in the urine, plasma and erythrocytes result from the adenosine deaminase deficiency. Increased concentrations of dATP and dADP in erythrocytes, lymphocytes and bone marrow cells and, in some instances, decreased concentration of ATP in crythrocytes from these patients result from the deoxyadenosine accumulation and may have toxic properties toward the immune system. ${ }^{60,72-76}$ Increased lymphocyte and platelet cyclic-AMP concentrations may also contribute to the dysfunction of these cells. ${ }^{77}$ A secondary severe deficiency of erythrocyte S-adenosyl-homocysteine hydrolase has been observed. ${ }^{78,79}$ This may be related to the deoxyadenosine accumulation, since deoxyadenosine has been shown to inactivate $\mathrm{S}$-adenosylhomocysteine hydrolase ${ }^{78}$ A possible interruption of methylation reactions by this inactivation may potentially contribute to the immunodefi- ciency and central nervous system disease. How these biochemical abnormalities lead to immune dysfunction is discussed below.

Adenosine deaminase is structurally altered in tissues from patients with severe combined immunodeficiency disease. ${ }^{80-85}$ The properties of the mutant enzymes provide support for genetic heterogeneity of the mutations involving the structural gene coding for adenosine deaminase. Structural alterations of adenosine deaminase also occur in patients with the enzyme deficiency and normal immune function. ${ }^{86,87}$ In these patients white cell adenosine deaminase is less severely deficient; this amount is adequate for normal function of the immune system.

Experimental therapies attempt to restore immune function in patients with severe combined immunodeficiency and adenosine deaminase deficiency. The results of these trials support an etiological relationship between the enzyme deficiency and the immune disorder. About $50 \%$ of the patients with severe combined immunodeficiency disease and adenosine deaminase deficiency respond to enzyme replacement therapy with packed irradiated erythrocytes ${ }^{88-91}$ The response includes an increase in the absolute lymphocyte count and improved responsiveness to the mixed lymphocyte culture and to phytohemagglutinin stimulation. As well, there is a diminution in the tissue deoxyadenosine triphosphate concentrations, a decrease in the excretion of adenosine and deoxyadenosine and an elevation of erythrocyte $\mathrm{S}$-adenosylhomocysteine hydrolase..$^{78.89-91}$ Bone marrow transplantation corrects most of the immunological and biochemical abnormalities ${ }^{91-93}$ and appears to be the treatment of choice. A low purine diet, which reduces the urinary excretion and the plasma concentrations of adenosine and deoxyadenosine, ${ }^{91}$ and thymosin administration may be useful adjuncts to the management of these patients. ${ }^{94}$

The molecular basis for the immune dysfunction has been assessed in cell culture models simulating adenosine deaminase deficiency. Cytoxicity or immunosuppression follow the addition of adenosine or deoxyadenosine to cultured diploid fibroblasts, human lymphoblasts, lymphosarcoma T-cells, Chinese hamster ovary cells, and mouse fibroblasts (Reviewed in Reference 95). These compounds also inhibit mitogenmediated lymphoblastogenesis and monocyte to macrophage transformation. Toxicity from adenosine or deoxyadenosine is potentiated with inhibition of adenosine deaminase by specific inhibitors, coformycin, deoxycoformycin or erythro-9(2-hydroxyl-3nonyl) adenine. A block of adenosine deaminase alone, or addition of deoxyguanosine may also have similar cytotoxicity or immunosuppressive effects. ${ }^{43,74,96-100}$ 
The biochemical features of cells susceptible to deoxynucleoside toxicity have been defined using cultured human lymphoblast cell lines. Deoxyadenosine is selectively toxic to cultured T-lymphoblasts during adenosine deaminase inhibition..$^{96,99,100}$ Deoxyadenosine mediated cytotoxicity in T-lymphoblasts is accompanied by increased concentrations of dATP. T-lymphoblasts have a $20-45$-fold greater capacity to accumulate deoxyadenosine nucleotides than Blymphoblasts at deoxyadenosine concentrations of 50 $\mu \mathrm{M} \cdot{ }^{101,102}$ The accumulation of deoxyadenosine nucleotides in $\mathrm{T}$-lymphoblasts may result from the small quantity of 5'-nucleotidase activity either on the plasma membrane $e^{5,101,102}$ or in the cytoplasm. ${ }^{25}$ Similarly, the lack of deoxyadenosine nucleotide accumula- tion in B-lymphoblasts may result from the high activity of 5 -nucleotidase in the cytoplasm ${ }^{25}$ or plasma membrane. ${ }^{58,101,102}$ The high 5 '-nucleotidase activity may degrade dAMP back to deoxyadenosine, preventing its conversion to dATP in B-lymphoblasts. A close correlation exists between plasma membrane $5^{\prime}$ nucleotidase and the ability to accumulate dATP, supporting a relationship between these two variables in murine lymphocytes. ${ }^{103}$ Since human thymocytes have 5 -nucleotidase activity as low as cultured Tlymphoblasts, ${ }^{58,104-106}$ human thymocytes may share common properties with $\mathrm{T}$-lymphoblasts and may be a cell at risk for toxicity when deoxynucleosides accumulate.

How does deoxynucleoside triphosphate accumula-

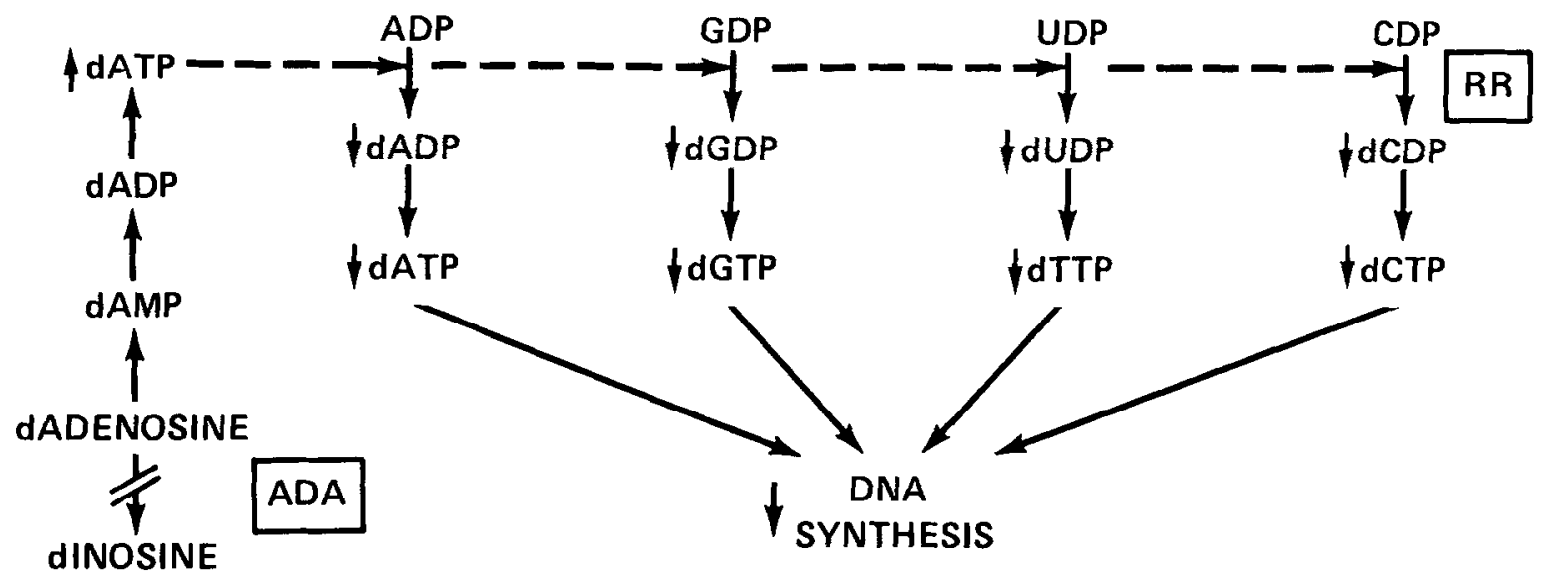

A

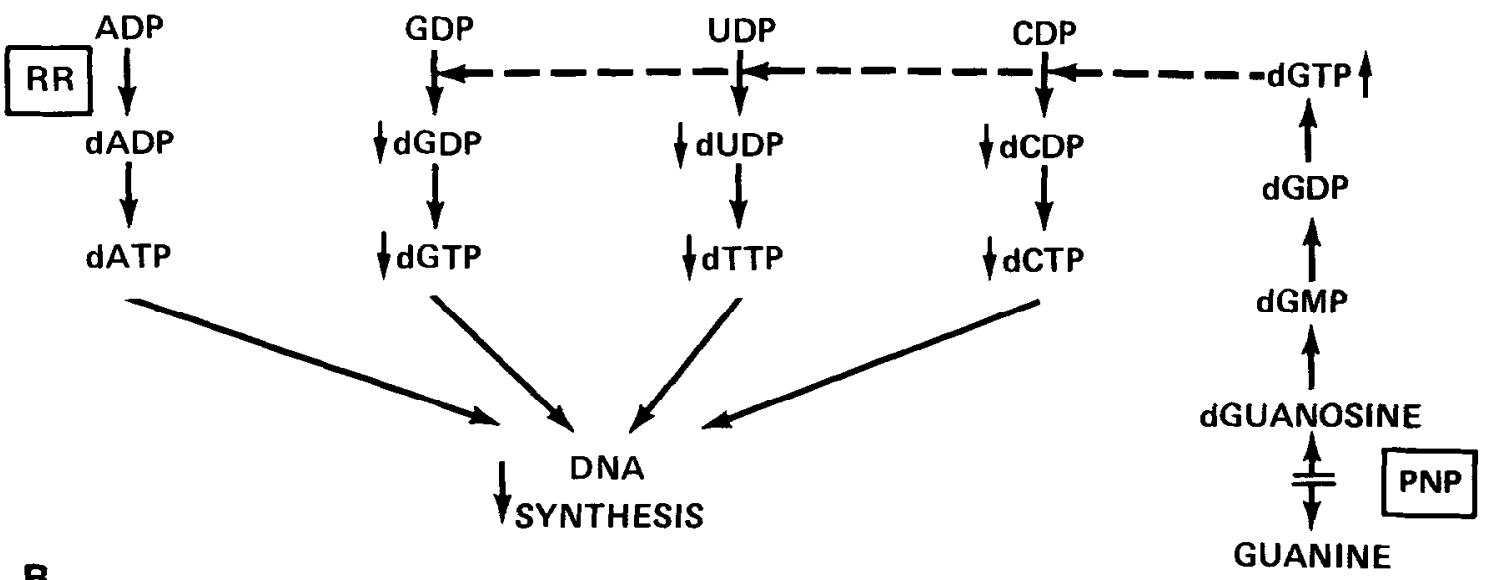

Fig. 3. Ribonucleotide reductase hypothesis. Ribonucleotide reductase (RR) is the enzyme that converts ADP, GDP, UDP, and CDP to AADP, dGDP, dUDP, and dCDP, respectively. (A) In adenosine deaminase (ADA) deficiency, deoxyadenosine cannot be deaminated to deoxyinosine, and is thus phosphorylated to dAMP, dADP, and dATP. The accumulation of dATP potently inhibits all the reactions of ribonucleotide reductase. This potent inhibitory effect may decrease the synthesis of dGDP, dUDP, and dCDP, reduce the substrates available for DNA synthesis and inhibit DNA synthesis. (B) In purine nucleoside phosphorylase (PNP) deficiency. deoxyguanosine, which ordinarily undergoes phosphorolysis to guanine is phosphorylated to dGMP. dGDP, and dGTP. Deoxyguanosine triphosphate accumulates in purine nucleoside phosphorylase deficiency and is a potent inhibitor of three of the four components of the ribonucleotide reductese reaction. Inhibition of these reactions can lead to a reduction of DNA synthesis. 
tion cause cell toxicity? A block at ribonucleotide reductase is currently the most popular hypothe$\mathrm{sis}^{43,72,73,97,98}$ (Fig. 3). This reaction leads to the synthesis of the deoxyribonucleoside triphosphate substrates necessary for DNA formation. It is potently inhibited by dATP. A block at ribonucleotide reductase from the accumulated dATP could explain immune dysfunction in the deficiencies of adenosine deaminase (Fig. 3). Resistance to deoxynucleoside toxicity with mutations of ribonucleotide reductase support the role of this enzyme in S-49 mouse T-lymphoma cells. ${ }^{107}$ The ribonucleotide reductase hypothesis is further strengthened by the reduction of DNA synthesis, but not RNA synthesis, during incubation with $50 \mu \mathrm{M}$ deoxyadenosine and an adenosine deaminase inhibitor in cultured human cells. ${ }^{108.109}$ However, the pattern of inhibition of DNA synthesis in these experiments was not similar to that expected for ribonucleotide reductase inhibition. ${ }^{108,109}$ Therefore, an additional or alternative mechanism of block of DNA synthesis needs to be considered.

Inhibition of intracellular methylation reactions provides an additional hypothesis to explain immune dysfunction. This possibility originates from the secondary decrease of erythrocyte S-adenosylhomocysteine hydrolase in adenosine deaminase deficiency ${ }^{78,79}$ An accumulation of S-adenosylhomocysteine, which may result from the hydrolase deficiency, inhibits methylation reactions and has cytotoxic and immunosuppressive activities. ${ }^{78,110-114}$ Although the exact mechanism for toxicity remains unclear, recent studies indicate that enzymatic methylation of phospholipids may be critical for the transduction of receptor mediated signals through cell membranes. ${ }^{115}$ A block of this reaction may also be toxic to cells of the human immune system. Deoxyadenosine, which accumulates in adenosine deaminase deficiency, irreversibly inactivates $\mathrm{S}$-adenosylhomocysteine hydrolase $\mathrm{e}^{78,114}$ and probably accounts for the secondary hydrolase deficiency (Fig. 4). However, this proposal remains unproven since elevated concentrations of S-adenosylhomocysteine have not been observed in cells from patients with adenosine deaminase deficiency. The selectivity of this mechanism may be directed toward B-lymphocytes. ${ }^{16}$

The hypothesis that increased levels of cAMP concentrations account for the immune dysfunction has been proposed based upon elevated cAMP concentrations in leukocytes and platelets from patients with adenosine deaminase deficiency. ${ }^{70,77}$ Adenosine increases cAMP concentrations in cells derived from the immune system by activating an adenosine receptor and stimulating plasma membrane adenylate cyclase. ${ }^{17 \cdot 120}$ Increased concentrations of cAMP inhibit

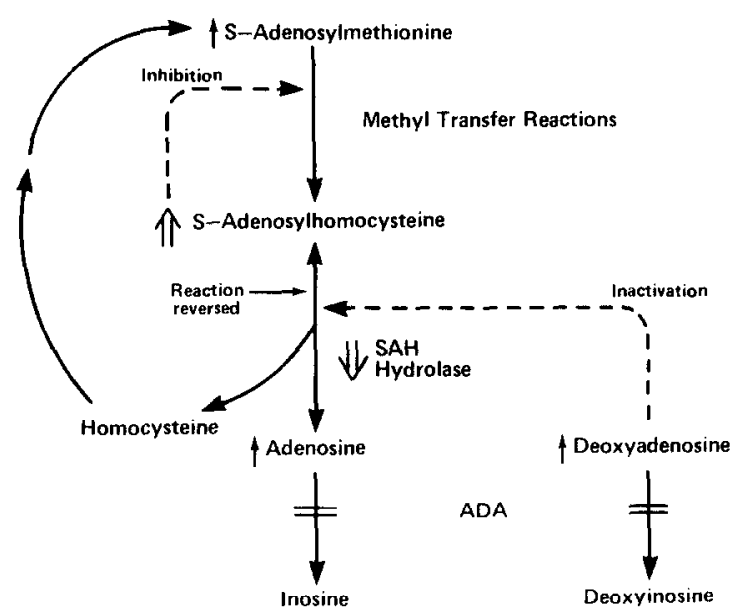

Fig. 4. Possible altered methylation in adenosine deaminase deficiency. This diagram shows the pathway involved in methyltransfer reactions catalyzed by S-adenosylmethionine. The product of these methyltransfer reactions is S-adenosylhomocysteine (SAH), a potent inhibitor of the S-adenosylmethionine mediated methyltransfer reactions. S-adenosylhomocysteine is removed by its degradation to homocysteine and adenosine. The adenosine is normally deaminated to inosine, thus ensuring the irreversibility of S-adenosylhomocysteine hydrolase. In adenosine deaminase (ADA) deficiency, there is an accumulation of adenosine and this may reverse the S-adenosylhomocysteine hydrolase reaction and cause an accumulation of S-adenosythomocysteine. As well, in adenosine deaminase deficiency, deoxyadenosine accumulates and this is known to cause suicide inactivation of S-adenysylhomocysteine hydrolase, which may lead to an accumulation of S-adenosylhomocysteine. The increased concentration of $\mathbf{S}$ adenosylhomocysteine could inhibit methyltransfer reactions and lead to toxic effects.

immune responsiveness and immune cytolysis. ${ }^{119.121}$ Elevated concentrations of cAMP may be responsible for decreased platelet aggregation in adenosine deaminase deficiency providing evidence for the operation of this mechanism. Increased levels of cAMP in cells remain a possible mechanism of immunodeficiency in adenosine deaminase deficiency.

Biochemical mechanisms other than the ones discussed above may account for the association between purine enzyme defects and immune disorders or more than one mechanism may be involved. Direct proof for a particular mechanism by its demonstration in the tissues of the enzyme deficient patient is not yet available.

Purine nucleoside phosphorylase deficiency. Purine nucleoside phosphorylase deficiency was first described in 1975 in association with a disturbance of cellular immunity. ${ }^{122}$ This autosomal recessive disturbance of $\mathrm{T}$-cell function is characterized by a marked reduction in T-lymphocyte numbers and by a lack of a proliferative response of lymphocytes to mitogens and allogencic cells. The normal induction of T-cell maturation in bone marrow precursors by human thymic epithelium conditioned medium or thymosin in two 
brothers with purine nucleoside phosphorylase deficiency suggest normal $\mathrm{T}$-cell generation and intact thymic epithelial function. ${ }^{123}$

Humoral immune function appears intact or enhanced as shown by normal or elevated immunoglobulin concentrations, normal numbers of peripheral B-lymphocytes, and normal antibody response to antigens. The occurrence of monoclonal gammopathy, rheumatoid factor, antinuclear antibody, and Coombspositive hemolytic anemia indicate excessive antibody production. ${ }^{123-125}$ Features resembling systemic lupus erythematosus are evident in some of these patients, suggesting that the enzyme deficiency may provide a model for this autoimmune disorder.

Patients with this disorder have evidence of a block of purine nucleotide degradation. There is decreased synthesis of uric acid with hypouricemia, hypouricosuria and an excessive urinary excretion of inosine, guanosine, deoxyinosine, and deoxyguanosine. ${ }^{46,122,}$ 124-127 Fructose infusion indicates a block of purine nucleotide degradation by no change in serum urate concentration or urinary uric acid and oxypurine excretion and a massive increase in urinary inosine excretion. ${ }^{46}$ These patients are overproducers of purines despite the hypouricemia. The overproduction of purines is accompanied by an elevation in the concentration of phosphoribosylpyrophosphate in erythrocytes to a level similar to that observed in patients with a deficiency of hypoxanthine-guanine phosphoribosyltransferase ${ }^{128}$ This is related to a loss of active reutilization of purine bases in purine nucleoside phosphorylase deficiency from the lack of formation of hypoxanthine or guanine, substrates for hypoxanthineguanine phosphoribosyltransferase. Deoxyguanosine triphosphate concentrations are elevated in erythrocytes ${ }^{60,129,130}$ This is believed to resuft from the accumulation of deoxyguanosine and its subsequent phosphorylation. Increased concentrations of dGTP may be the toxic factor to the immune system. The degree of abnormality in uric acid levels, nucleoside excretion, and dGTP concentrations reflect the severity of the enzyme deficiency. ${ }^{130}$ These patients also have an $80 \%$ decrease in erythrocyte S-adenosylhomocysteine hydrolase activity ${ }^{79}$ but the significance of this observation remains unclear.

Structural alterations of the decreased purine nucleoside phosphorylase provides evidence for structural gene mutations and genetic heterogeneity in this disorder. ${ }^{130-134}$

Enzyme replacement therapy with blood transfusions have only partial success in patients with purine nucleoside phosphorylase deficiency. ${ }^{135-137}$ Two of four patients have modest improvement. There is an increase in the percentage of peripheral E-rosette forming cells without an increase in the lymphocyte count. The lymphocytes stimulate with phytohemagglutinin. A slight reaction to skin tests became evident in one patient. Transfusion therapy in these patients increases the serum urate concentration and the urine uric acid excretion and decreases urine nucleoside excretion. ${ }^{123,135,136}$ Partial and transient responses to thymosin administration or thymus epithelial transplants are reported. ${ }^{137}$ Administration of uridine and hypoxanthine with or without allopurinol has no apparent beneficial effect on the immune function. Since in vitro studies suggest that deoxycytidine may reverse deoxyadenosine or deoxyguanosine induced toxicity, ${ }^{43,96-100}$ it is possible that this therapy in patients may be helpful.

The molecular pathology by which the enzyme deficiency causes the immune dysfunction may be related to deoxyguanosine accumulation. Deoxyguanosine is toxic to T-lymphoblasts and not to B-lymphoblasts. ${ }^{96-98,138}$ T-lymphoblasts accumulate dGTP and B-lymphoblasts do not. Inhibition of ribonucleotide reductase by dGTP and subsequent inhibition of DNA synthesis is the major mechanism by which toxicity to the immune system may occur ${ }^{109}$ (Fig. 3B). The role of a decrease in S-adenosylhomocysteine hydrolase in this disease has not been defined. ${ }^{79}$

Myoadenylate deaminase deficiency. A new enzyme deficiency associated with myopathy has been recognized in a series of 5 cases of 250 biopsies. ${ }^{139}$ All patients were young males with muscle weakness or cramping after exercise, in many instances since childhood. Decreased muscle mass, hypotonia and weakness are evident on physical exam. There is a mildly elevated creatine phosphokinase and nonspecifically abnormal electromyograms. Although the patients release lactate into the venous blood during exercise, there is a failure to release ammonia. While the muscle biopsy is normal, the stain for adenylate deaminase is negative. Ilomogenized muscle is deficient in adenylate deaminase, while the enzyme is normal in erythrocytes and neutrophils.

The original observations about this disorder have been expanded ${ }^{140,141}$ and now are confirmed by other workers. ${ }^{142}$ Males and females may have this disorder. Three of 6 female patients have a poorly understood associated collagen disease such as systemic lupus erythematosus, polymyositis or mixed connective tissue disease. ${ }^{143}$ Rabbit antiserum to human purified myoadenylate deaminase reacts with human enzyme from muscle, but not from erythrocytes, neutrophils or platelets. ${ }^{140}$ The data suggest a separate genetic origin for the muscle enzyme and explains the basis for a deficiency of the muscle enzyme alone.

The frequency (5-6 per 250 muscle biopsies) $)^{139,142}$ of 
the enzyme deficiency and the diversity of patients involved have suggested that this enzyme deficiency may represent a normal variant or a subclinical state rather than an actual disease. ${ }^{142}$ However, recent experiments indicate an important possible role of adenylate deaminase in the maintenance of a normal adenine nucleotide pool. ${ }^{144}$ ATP depletion is accelerated in the contracting muscle from a patient with this enzyme deficiency. This may be related to the interruption of the purine nucleotide cycle of muscle. ${ }^{37}$

Xanthine oxidase deficiency. Xanthinuria is a rare disorder characterized by low serum urate concentrations and urinary uric acid excretion and elevated urinary excretion of hypoxanthine and xanthine (Reviewed in Reference 145). This autosomal recessively inherited disease is associated with a gross deficiency of xanthine oxidase in the jejunal mucosa or liver. Xanthine stones, hypoxanthine and xanthine in muscle, and osteoarthritis have been observed in this disorder. Fructose infusion in a patient with xanthine oxidase deficiency shows an increase of urinary hypoxanthine and no change in the serum urate level or urinary uric acid excretion. These changes illustrate the block in purine nucleotide degradation at xanthine oxidase. ${ }^{47}$

Guanine deaminase deficiency. The complete absence of guanine deaminase activity and of the inhibitory protein has been reported in a single newborn, full-term boy, who died two days after birth. ${ }^{146}$ No specific clinical features were described. It remains unclear what is the significance of this association of guanine deaminase with newborn death.

\section{Increased Degradation}

Increased nucleotide degradation may occur by a number of different mechanisms which alter the regulation of the pathway. If the subsequent purine catabolic pathway is not blocked, this may result in an increased synthesis of uric acid and may be clinically expressed as hyperuricemia, hyperuricosuria and gout. Not all disorders of nucleotide degradation ultimately alter uric acid synthesis.

Increased enzyme activity. A 45-70-fold increase of erythrocyte adenosine deaminase activity has been observed in the kindred with hereditary hemolytic anemia. ${ }^{39}$ Patients with this dominantly inherited entity have a mild anemia and a decrease of erythrocyte adenine nucleotide levels to less than $50 \%$ of that comparable with reticulocyte-rich blood. The decreased erythrocyte adenine nucleotide concentration appears to be responsible for the hemolytic anemia. This may result from diminished reutilization of adenosine to AMP as a result of excessive destruction of adenosine by elevated adenosine deaminase activity.

Hepatic xanthine oxidase is increased in gouty patients who exhibit an overproduction of uric acid and in one patient with a partial deficiency of hypoxanthine-guanine phosphoribosyltransferase. ${ }^{147,148}$ This may be a secondary change related to the induction of xanthine oxidase. ${ }^{145}$ Administration of RNA, hypoxanthine, ethylaminothiadiazole or fructose to human subjects causes liver xanthine oxidase to increase from 2 to 4 times higher than the control group. ${ }^{147}$

Decreased reutilization and increased substrate. Seventy-five percent of adenine nucleotide degraded to hypoxanthine in normal individuals is reutilized to $1 \mathrm{MP} .{ }^{48}$ This may represent an important homeostatic mechanism for the maintenance of the nucleotide pool, since a loss of this pathway leads to increased purine excretion and elevated IMP formation by de novo purine synthesis. ${ }^{149}$ The formation of increased quantities of nucleotides by this mechanism or by increased nucleic acid degradation will provide increased substrate for the purine catabolic pathway and will result in an accelerated rate of degradation.

The ability to reutilize hypoxanthine is lost in hypoxanthine-guanine phosphoribosyltranferase deficiency. ${ }^{48}$ Patients with this $\mathrm{X}$-linked enzyme deficiency overproduce uric acid and develop hyperuricemia and hyperuricosuria. ${ }^{149}$ The inability to reutilize hypoxanthine is an important contributor to purine overproduction in these patients, since oxidation to uric acid then remains the only pathway for hypoxanthine metabolism. Inability to reutilize hypoxanthine and increased activity of purine biosynthesis de novo from increased intracellular phosphoribosylpyrophosphate together account for the overproduction of uric acid (Fig. 5). In the complete enzyme deficiency, patients have Lesch-Nyhan syndrome, a disorder characterized by self-mutilation, choreoathetosis. mental retardation, spasticity and uric acid calculi (Reviewed in Reference 149). In the partial enzyme deficiency, patients have Kelley-Seegmiller syndrome, a disorder characterized by gout, recurrent uric acid calculi and occasional mild central nervous system disorders (Reviewed in Reference 149). In purine nucleoside phosphorylase deficiency (described above), there is a secondary loss of hypoxanthine reutilization and increased de novo purine synthesis. This results from the inability to form hypoxanthine, a product of purine nucleoside phosphorylase, and increased intracellular phosphoribosylpyrophosphate levels, respectively.

The complete deficiency of adenine phosphoribosyltransferase is characterized by a loss of the ability to 


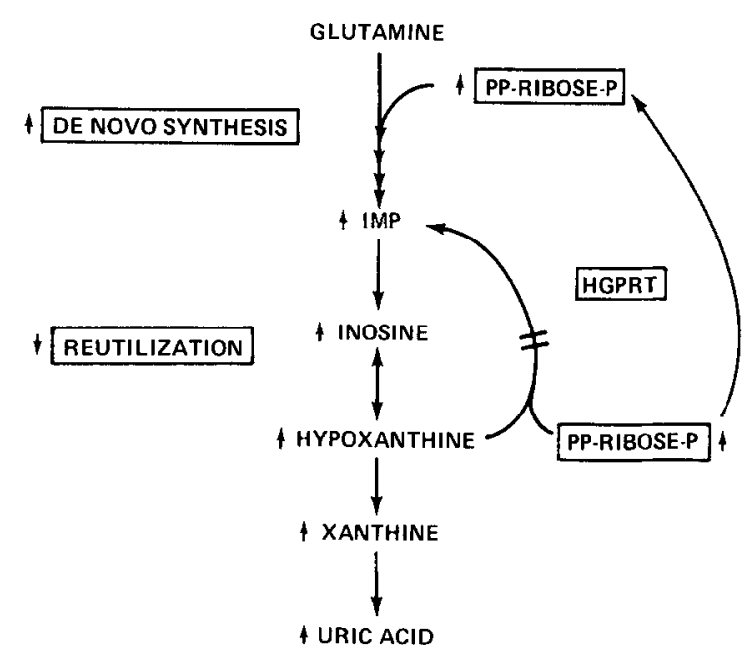

Fig. 5. Mechanism for hyperuricemia in hypoxanthine-guanine phosphoribosyltransferase (HGPRT) deficiency. The absence of HGPRT leads to a loss in the ability to reutilize hypoxenthine. Thus all hypoxanthine formed is oxidized to uric acid. The decreased hypoxanthine reutilization leads to a sparing of PPribose-P, the other substrate for HGPRT. PP-ribose-P is a ratelimiting substrate for purine biosynthesis de novo. The resultant elevated intracellular concentration of PP-ribose-P causes an increase in purine biosynthesis de novo. Thus both decreased reutilization of hypoxanthine and increased purine biosynthesis de novo lead to overproduction of uric acid in HGPRT deficiency.

reutilize adenine. There results an excessive excretion of adenine and its oxidation product, 2,8-dihydroxadenine. ${ }^{150,151}$ The increased degradation of these compounds is small in relation to total purine excretion. However, 2,8-dihydroxyaderine is insoluble and stones composed of this compound are formed. The major feature of almost all patients with this autosomal recessively inherited disorder is recurrent renal calculi formed from adenine and its oxidation products. Since these stones are similar to uric acid, they may be erroneously identified as such. These patients have a normal serum urate concentration and no cvidence for gout. In contrast to the complete deficiency, the partial deficiency of adenine phosphoribosyltransferase has no definite associated clinical features. ${ }^{152}$

Increased substrate alone may cause elevated purine nucleotide degradation. An error of purine metabolism, increased activity of phosphoribosylpyrophosphate synthetase, leads to increased intracellular concentrations of phosphoribosylpyrophosphate and increased de novo purine synthesis (Reviewed in Reference 153). In this rare X-linked disorder ${ }^{154}$ there is a massive overproduction of uric acid with gout and uric acid calculi, but no evidence of central nervous system dysfunction. A large tumor or hyperplastic tissue may have increased turnover of nucleic acid (Reviewed in Reference 153) and generate increased nucleotide substrate for degradation. This may result in increased synthesis of uric acid. Hematological malignancies or other hematological disorders leading to bone marrow hyperplasia classically cause hyperuricemia on this basis. In psoriasis, the increased turnover of epithelial tissue may lead to hyperuricemia by means of increased synthesis of uric acid.

Decreased ATP. A sudden diminution of ATP concentration and the resultant elevation of AMP and IMP levels appear to activate a cascade of nucleotide breakdown to purine catabolic intermediates and uric acid. A substantial decrease in the intracellular concentration of ATP may result in profound morphological and functional changes with persistent $\Lambda T P$ levels of $20 \%-25 \%$ of control values. ${ }^{155}$ In the myocardium there is a correlation between a diminution of ATP content of muscle and impairment of left ventricular function. ${ }^{156}$ Hypophosphatemia leads to decreased ATP concentrations and heart failure er $^{157-159}$ or even rhabdomyolysis. ${ }^{160}$ In myocardial ischemia the degree of ATP loss is correlated with a lethal injury. ${ }^{161,162}$

(A) Increased degradation of ATP. Increased degradation of ATP has been described above for the fructose infusion model, where ATP is consumed in the formation of fructose-1-P, and in muscular exercise, where ATP is consumed during contraction of actin and myosin.

Hyperuricemia, gouty arthritis and uric acid calculi may complicate the clinical course of Glycogen Storage Disease Type I. ${ }^{163,164}$ The glucose-6-phosphatase deficiency may activate a mechanism similar to fructose-induced hyperuricemia. ${ }^{165-167}$ In this disorder the triggering mechanism for increased production of uric acid may be the insulin counter-regulatory hormonal response to hypoglycemia and the inability to synthesize glucose (Fig. 6). Recent studies indicate that parenteral glucagon causes a rise in the serum urate level and urinary uric acid excretion in enzyme deficicnt paticnts. ${ }^{166}$ This activity of glucagon is accompanied by a reduction in hepatic ATP concentrations and a marked elevation of glucose-6-phosphate, fructose-6-phosphate and fructose-1,6-diphosphate. ${ }^{167}$ The depletion of ATP and the trapping of inorganic phosphate in the form of phosphorylated sugar compounds set the stage for activation of purine nucleotide degradation and may explain the increased synthesis of uric acid (Fig. 6). The elevated rate of purine biosynthesis de novo observed in this disease ${ }^{163.164}$ may result secondarily from the depletion of the adenine nucleotide pool. Increased lactate formation inhibits the renal excretion of urate and accentuates the hyperuricemia. Further support for the operation of these mechanisms is derived from the therapeutic approach of providing continuous nutrition and preventing hypoglycemia and 
Fig. 6. Mechanisms for hyperuricemia in glucose-6-phosphatase (GL-6-P'ASE) deficiency. Hypoglycemia may be the trigger for the abnormalities in this enzyme deficiency. Hypoglycemia causes glucagon release and this activates glycogen phosphorylase to degrade glycogen to glucose-6-phosphate. There results an increased intracellular concentration of glucose-6-phosphate, fructose-6-phosphate and fructose-1,6diphosphate. These events lead to a depletion of ATP concentrations, an activation of purine nucleotide degradation and increased synthesis of uric acid. The increased accumulation of phosphorylated sugars leads to hyperlacticacidemia and this decreases the renal excretin of urate.

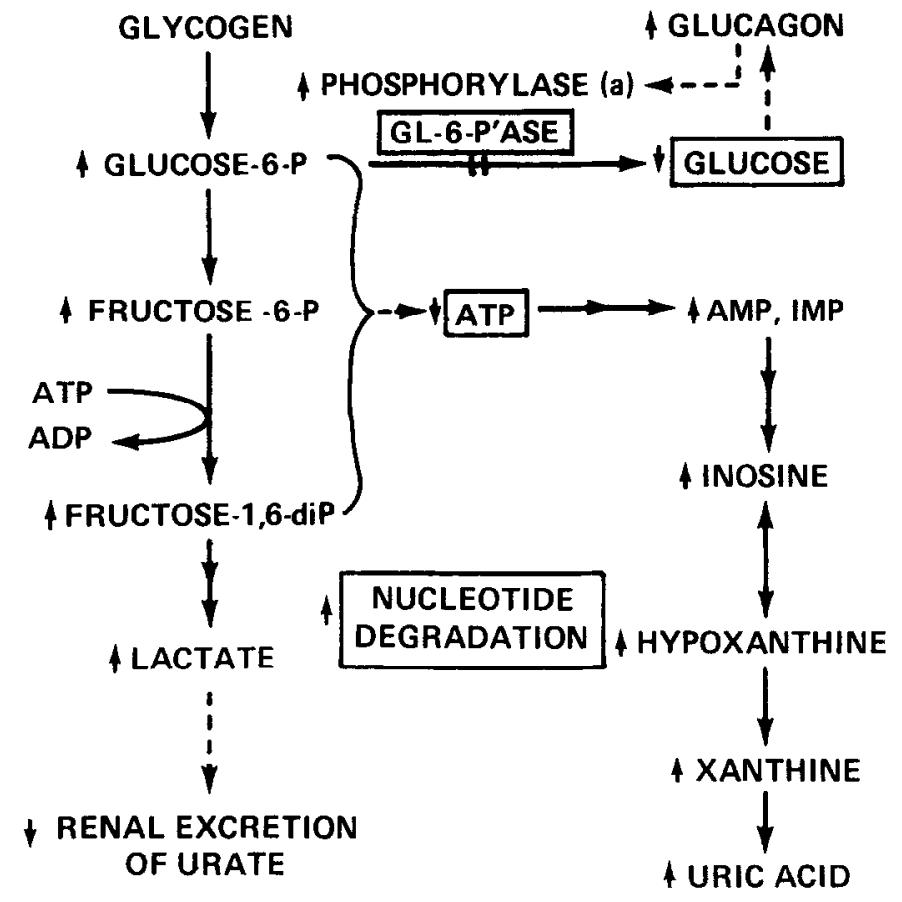

A lack of any of these components will impair ATP synthesis. The resultant decrease of ATP concentration may trigger a cascade of purine nucleotide degradation as described above. Tissue hypoxia and hypophosphatemia are recognized causes of decreased ATP synthesis. The effects of hypophosphatemia were described above. ${ }^{157-160}$

Tissue hypoxia has been a well recognized cause of cellular adenine nucleotide depletion. The adenine nucleotide depletion is accompanied by the appearance of purine catabolic intermediates, which are metabolic markers for tissue ATP degration. In ischemic mammalian myocardium there is a marked decrease in ATP and creatine phosphate levels, with an increase in organic phosphate, inosine, adenosine, IMP, and a small increase in ADP and AMP concentrations. ${ }^{162,169,170}$ Inorganic phosphate, inosine, and hypoxanthine have been measured in myocardial venous drainage and found to correlate with adenine nucleotide and phosphocreatine depletion over hypoxia in dog heart muscle. ${ }^{171}$ In sequential biopsies during experimental myocardial infarction in dogs a substantial diminution of ATP content occurs in both infarcted and noninfarcted areas of the heart as compared to uninjured cardiac muscle. ${ }^{172.173}$ Similar mechanisms appear to exist in humans since elevated concentrations of adenosine or hypoxanthine have been detected in coronary sinus blood of patients with angina pectoris induced by atrial pacing..$^{74-176}$

Evidence for depletion of tissue adenine nucleotides and release of purine nucleotide degradation interme-

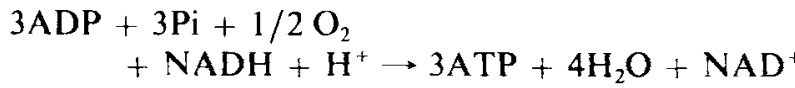


diates have been observed in other situations including hemorrhagic shock, hypoxia, hypothermia, renal ischemia, hyperthermic stress, muscle ischemia, and brain ischemia in animals. ${ }^{177-193}$ Elevated blood levels of uric acid, allantoin or hypoxanthine provide a useful plasma correlation with these changes. Allantoin, an oxidation product of uric acid, is the end-product of purine metabolism in certain animals. In humans, hyperuricemia may result from diseases leading to tissue hypoxia. In acute myocardial infarction in man there is hyperuricemia with an expansion of the uric acid pool and an increased uric acid turnover rate. ${ }^{194-197}$ Hyperuricemia also occurs during human circulatory collapse, ${ }^{198}$ smoke inhalation, ${ }^{199}$ respiratory acidosis, ${ }^{200}$ and decompensation in chronic bronchitis. ${ }^{201}$ Increased serum urate concentrations and urinary uric acid excretion are observed to accompany perinatal hypoxia. ${ }^{202}$ Respiratory distress syndrome or other hypoxic problems are accompanied by more pronounced increases of these variables ${ }^{202}$ and by elevated plasma, ${ }^{203}$ cerebrospinal fluid, ${ }^{204}$ urinary ${ }^{205}$ or renal tissue ${ }^{206}$ hypoxanthine concentration.

The prevention of further purine nucleotide degradation and stimulation of ATP synthesis together with the reversal of the precipitating factor may provide an optimal approach for the management of patients with decreased synthesis of ATP. The consequences of hypophosphatemia may be managed by inorganic phosphate replacement therapy. In tissue hypoxia, increased synthesis of ATP may be promoted by reversal of hypoxia and by different combinations of allopurinol, hypoxanthine, adenine, inosine, Kreb's cycle intermediates, and glucose, potassium and insulin. Therapy of myocardial infarction is aimed at increasing ATP synthesis and decreasing its utilization by improving myocardial perfusion, augmenting ATP production by anerobic glucolysis with glucoseinsulin-potassium and hypertonic glucose, and reducing myocardial ATP consumption by beta blocking agents and balloon counter-pulsation. ${ }^{207}$ Glucose, insulin and potassium or inhalation of an oxygen rich gas mixture have been found to minimize cardiac necrosis and to maintain ATP levels in the infarcting myocardium ${ }^{208}$ or to have an inotropic response in congestive heart failure. ${ }^{209}$ Inosine, a purine nucleoside, improves the performance of ischemic myocardium $^{210}$ and enhances the preservation of ischemic kidney. ${ }^{211}$ Inosine increases ATP levels by its degradation to hypoxanthine and ribose-l-phosphate, compounds which promote ATP synthesis. ATP-Mg increases ATP concentrations during hepatic ischemia. $^{212}$

Allopurinol may be useful in the management of disorders of purine nucleotide degradation by blocking the pathway at xanthine oxidase and preventing the conversion of hypoxanthine to useless metabolic end products. The accumulated hypoxanthine could be reutilized to form nucleotides and ultimately ATP. ${ }^{213}$ In tissues known not to contain xanthine oxidase. allopurinol may be active at another site either directly or as one of its metabolites. ${ }^{25}$ In humans, allopurinol is rapidly oxidized to oxipurinol by xanthine oxidase. Allopurinol or oxipurinol may be phosphorylated to ribonucleotide derivatives. ${ }^{214-216} \mathrm{~A}$ modification of purine nucleotide degradation by allopurinol is supported by its stimulation of hypoxanthine or adenine uptake into myocardial cell nucleotides. ${ }^{217}$

Pretreatment with allopurinol usually improves function and nucleotide levels, but treatment after the acute event may not be consistently effective. Sodium allopurinol in dosages ranging from $50-100 \mathrm{mg} / \mathrm{kg}$ has been shown to reverse the effects of experimental myocardial hypoxia, ${ }^{218,219}$ and irreversible hemorrhagic shock in dogs treated with hypoxanthine. ${ }^{220}$ In a similar experiment, allopurinol, adenine, hypoxanthine and oxaloacetate produced the best survival (43\%). ${ }^{222}$ Allopurinol has also been found to preserve kidneys $^{223,224}$ and small intestine $e^{225}$ and to increase hepatic adenine nucleotide resynthesis after oligemia, ${ }^{226}$ further demonstrating a potential role in maintaining normal cell integrity during ischemia. However, this drug did not modify infarct size when administered 15 minutes after infarction, ${ }^{227}$ perhaps because an irreversible depletion of ATP had already occurred.

The application of these promising experimental observations to human disease processes that have proven refractory to current management appears to be indicated.

\section{SUMMARY AND CONCLUSIONS}

The pathway of purine nucleotide degradation is a regulated series of reactions by which purine ribonucleotides are degraded to uric acid in man. Two major categories of disorders occur. A block of degradation is associated with syndromes involving immune dysfunction, myopathy or renal calculi. Increased degradation of nucleotides occurs with syndromes characterized by hyperuricemia, gout, renal calculi, anemia or acute hypoxia. Some disorders associated with increased purine nucleotide degradation are characterized by marked decreases in intracellular ATP concentration and increases in the serum urate concentration and elevated uric acid, oxypurine, and inosine excretion.

Management of disorders of purine nucleotide degradation is dependent upon an understanding of the metabolic mechanisms of the disease state. In blocks of the pathway, symptomatic therapy may 
reverse the consequence of the block. In other instances, specific biochemical therapy to correct an enzymatic defect has been attempted, including enzyme replacement therapy. Patients with increased purine nucleotide degradation with overproduction of uric acid need protection from the adverse effects of excess uric acid production. This is achieved by inhibiting uric acid synthesis with allopurinol. Patients with disorders leading to decreased intracellular concentrations of ATP require therapy to reverse the underlying disorder, to inhibit further purine nucleotide degradation and to stimulate ATP synthesis.

Application of the promising experimental observations about the molecular pathology underlying disorders of purine nucleotide degradation will provide innovative approaches to diagnosis and management of the associated diseases. Already, concepts of enzyme blocks and alteration of immune function has lead to clinical trials of deoxycoformycin, a potent inhibitor of adenosine deaminase. ${ }^{228-231}$

\section{REFERENCES}

1. Lomax CA, Henderson JF: Adenosine formation and metabolism during adenosine triphosphate catabolism in Ehrlich ascites tumor cells. Cancer Res 33:2825-2829, 1973

2. Lomax CA, Bagnara AS, Henderson JF: Studies of regulation of purine nucleotide catabolism. Can J Biochem 53:231-241, 1975

3. McComb RB, Yushok WD: Metabolism of ascites tumor cells IV. Enzymatic reaction involved in adenosine triphosphate degradation induced by 2-deoxyglucose. Cancer Res 24:198-203, 1964

4. Overgaard-Hansen K: Metabolic regulation of the adenine nucleotide pool 1 . Studies on the transient exhaustion of the adenine nucleotides by glucose in Ehrlich ascites tumor cells. Biochim Biophys Acta 104:330-347, 1965

5. Fox IH, Kelley WN: Studies on the mechanism of fructoseinduced hyperuricemia in man. Metabolism 21:713-721, 1972

6. Narins RG, Weisberg JS, Meyers AR: Effects of carbohydrate on uric acid metabolism. Metabolism 23:455-465, 1974

7. Perheentupa J, Raivio K: Fructose-induced hyperuricemia. Lancet 2:528-531, 1967

8. Raivio KO, Becker MA, Meyer LJ, et al: Stimulation of human purine synthesis de novo by fructose infusion. Metabolism 24:861-869, 1975

9. Simkin PA: Hexose infusions in cebus monkeys: Effects on uric acid metabolism. Metabolism 21:1029-1036, 1972

10. Bode IC, Zelder $\mathrm{O}$, Rumpelt $\mathrm{HJ}$, et al: Depletion of liver adenosine phosphates and metabolic effects of intravenous infusion of fructose or sorbital in man and in the rat. Europ $J$ Clin Invest 3:436-441, 1973

11. Knochel JP, Dotin LN, Hamburger R: Heat, stress, exercise and muscle injury: Effects on urate metabolism and renal function. Ann Int Med 81:321-328, 1974

12. Rakestraw NW: Chemical factors in fatigue. 1. The effects of muscular exercise upon certain common blood constituents. J Biol Chem 47:565-591, 1921

13. Sutton J, Toews CJ, Ward GR, et al: Purine metabolism during strenuous muscular exercise in man. Metabolism 29:254260,1980

14. Fox IH: Degradation of purine nucleotides, in Kelley WN, Weiner IM (eds): Handbook of Experimental Pharmacology, vol 5. New York, Springer-Verlag, 1978, pp 93-124

15. Solyom A, Trams EG: Enzyme markers in characterization of isolated plasma membranes. Enzyme 13:329-372, 1972

16. DePierre JW, Karnovsky ML: Ecto-enzymes of the guinea pig polymorphonuclear leukocyte $\mathrm{I}$. Evidence for an ecto-adenosine monophosphatase,-adenosine triphosphatase, and -p-nitrophenyl phosphatase. J Biol Chem 249:7111-7120, 1974

17. DePierre JW, Karnovsky ML: Ecto-cnzymes of the guinea pig polymorphonuclear leukocyte II. Properties and suitability as markers for the plasma membrane J Biol Chem 249:7121-7129, 1974
18. Farquhar MG, Bergeron JJM, Palade GE: Cytochemistry of golgi fractions prepared from rat liver. J Cell Biol 60:8-25, 1974

19. Misra DN, Gill TJ III, Estes LW: Lymphocyte plasma membranes II. Cyto-chemical localization of 5'-nucleotidase in rat lymphocytes. Biochim Biophys Acta 352:455-461, 1974

20. Woo Y, Manery JF: 5'-Nucleotidase. An ecto-enzyme of frog skeletal muscle. Biochim Biophys Acta 397:144-152, 1975

21. Stefanovic V, Mandel P, Rosenberg A: Ecto-5'-nucleotidase of intact cultured C6 rat glioma cells. J Biol Chem 251:3900-3905, 1976

22. Frick GP, Lowenstcin JM: Studies of 5 -nucleotidase in the perfused rat heart. J Biol Chem 25:6372-6378, 1976

23. Fox IH, Marchant PJ: Purine catabolism in man: Inhibition of 5'-phosphomonoesterase activities from placental microsomes Can J Biochem 54:1055-1060, 1976

24. Frick GP, Lowenstein JM: Vectorial production of adenosine by $5^{\prime}$-nucleotidase in the perfused rat heart. J Biol Chem 253:1240 1244,1978

25. Edwards NL, Recker DP, Manfredi $J$, et al: Roles of cytoplasmic and plasma membrane 5 '-nucleotidase in regulating intracellular nucleotide levels. Clin Res 28:345A, 1980

26. Itoh R, Mitsui A, Tsushima K: $5^{\prime}$-Nucleotidase of chicken liver. Biochim Biophys Acta 146:151-159, 1967

27. Naito $Y$, Tsushima K: Cytosol 5'-nucleotidase from chicken liver. Biochim Biophys Acta 438:159-168, 1976

28. Fritzson P: Nucleotidase activities on the soluble fraction of rat liver homogenate. Partial purification and properties of 5'nucleotidase with pH optimum 6.3. Biochim Biophys Acta 178:534 541,1969

29. Van Den Derghe G, Van Pottelsburghe C, Hers HJ: A kinetic study of the soluble $S^{\prime}$-nucleutidase of rat liver. Biochem $J$ 162:611-616, 1977

30. Fritzson P: Regulation of nucleotidase activities in animal tissues. Adv Enz Reg 16:43-61, 1978

31. Hers H, Van Den Berghe G: Enzyme defect in primary gout. The Lancet 1:585-586, 1979

32. Van Den Berghe G, Bronfman M, Vanneste R, et al: The mechanism of adenosine triphosphate depletion in the liver after a load of fructose: a kinetic study of adenylate deaminase. Biochem $\mathrm{J}$ 162:601-609, 1977

33. Wheeler TJ, Lowenstein JM: Adenylate deaminase from rat muscle: regulation by purine nucleotides and orthophosphate in the presence of $150 \mathrm{mM} \mathrm{KCL}$. J Biol Chem 254:8994-8999, 1979

34. Snyder F, Henderson JF: Effects of elevated intracellular ATP and GTP concentrations on purine ribonucleotide synthesis and interconversions. Canad J Biochem 51:943-948, 1973

35. Barankiewicz J, Henderson JF: Effect of lowered intracellular ATP and GTP concentrations on purine ribonucleotide synthesis and interconversions. Canad J Biochem 55:257-262, 1977 
36. Lomax CA, Bagnara AS, Henderson JF: Studies on the regulation of purine nucleotide catabolism. Canad J Biochem 53:231-241, 1975

37. Lowenstein JM, Goodman MN: The purine nucleotide cycle in skeletal muscle. Fed Proc 37:2308-2312, 1978

38. Kelley WN, Rosenbloom FM, Henderson JF, et al: A specific enzyme defect in gout associated with overproduction of uric acid. Proc Natl Acad Sci USA 57:1735-1739, 1967

39. Valentine WN, Paglia DE, Tartaglia AP, et al: Hereditary hemolytic anemia with increased red cell adenosine deaminase (45-70-fold) and decreased adenosine triphosphate. Science 195:783-785, 1977

40. Palella T. Andres CM, Fox 1H: Human placental adenosine kinase: Kinetic mechanism and inhibition. I Biol Chem 255:52645269,1980

41. Streeter DG, Simon LN, Robins RK, et al: The phosphorylation of ribavirin by deoxyadenosine kinase from rat liver. Differentiation between adenosine and deoxyadenosine kinase. Biochem 13:4543-4549, 1974

42. Krygier V, Momparler L: Mammalian deoxynucleoside kinases. II. Deoxyadenosine kinase: Purification and properties. J Biol Chem 246:2745-2751, 1971

43. Carson DA, Kaye J, Seegmiller JE: Lymphospecific toxicity in adenosine deaminase deficiency and purine nucleoside phosphorylase deficiency: Possible role of nucleoside kinase(s). Proc Natl Acad Sci 74:5677-5681, 1977

44. Andres CM, Fox IH: Purification and properties of human placental adenosine kinase. J Biol Chem 254:11388-11393, 1979

45. Ullman B, Gudas LJ, Cohen A, et al: Deoxyadenosine metabolism and cytotoxicity in cultured mouse T-lymphoma cells: A model of immunodeficiency disease. Cell 14:365-375, 1978

46. Edwards NL, Gelfand E, Biggar D, et al: Partial deficiency of purine nucleoside phosphorylase: Studies of purine and pyrimidine metabolism. J Lab Clin Med 91:736-749, 1978

47. Dwosh IL, Roncari D, Marliss E, et al: Hypouricemia in disease: A study of two different mechanisms. J Lab Clin Med 90:153-161, 1977

48. Edwards NL, Recker DP, Fox IH: Overproduction of uric acid in hypoxanthine guanine phosphoribosyltransferase deficiency. Contribution by impaired purine salvage. J Clin Invest 63:922-930, 1979

49. Edwards NL, Cassidy JT, Fox IH: Lymphocyte $5^{\prime}$-nucleotidase deficiency: Clinical characteristics of the associated hypogammaglobulinemia. Clin Immunol Immunopathol 17:76-88, 1980

50. Fox IH: Human ribonucleotide catabolism: Clinical and biochemical significance. Nutr Metab 16:65-78, 1974

51. Johnson SM, Asherson GL, Watts RWE, et al: Lymphocyte purine $5^{\prime}$-nucleotidase deficiency in primary hypogammaglobulinemia. Lancet 1:168 170, 1977

52. Edwards NL, Magilavy DB, Cassidy JT, et al: Lymphocyte ecto-5'-nucleotidase deficiency in agammaglobulinemia. Science 201:628-630, 1978

53. Webster ADB, North M, Allsop J, et al: Purine metabolism in lymphocytes from patients with primary hypogammaglobulinemia. Clin Exp Immunol 31:456-463, 1979

54. Recker DP, Edwards NL, Fox IH: Histochemical evaluation of lymphocytes in hypogammaglobulinemia: Decreased number of 5 '-nucleotidase positive cells. J Lab Clin Med 95:175-179, 1980

55. Matamoros N, Horwitz DA, Newton C, et al: Histochemical studies for 5'-nucleotidase and alpha-naphthyl (non-specific) esterase in lymphocytes from patients with primary immunoglobulin deficiencies. Clin Exp Immunol 36:102-106, 1979

56. Thompson LF, Boss GR, Spiegelberg HL, et al: Ecto-5'nucleotidase activity in $\mathrm{T}$ and $\mathrm{B}$ lymphocytes from normal subjects and patients with congenital X-linked agammaglobulinemia J Immunol 123:2475-2478, 1979

57. Rowe M, DeGast CG, Platts-Mills TAE, et al: $5^{\prime}$-nucleotidase of $B$ and $T$ lymphocytes isolated from human peripheral blood Clin Exp Immunol 36:97-101, 1979

58. Edwards NL, Burk L, Gelfand EW, et al: Variation of 5 '-nucleotidase activity in human mononuclear cells. Proc Natl Acad Sci USA 76:3474-3476, 1979

59. Fdwards NL, Fox IH: Technical Comment. Science 205:521. 1979

60. Mejias E, Mitchell BS, Cassidy JT, et al: Deoxyribonucleoside triphosphate pools in immunodeficiency states. Clin Res 27:331 A, 1979

61. Boss GR, Thompson LF, Jansen W, et al: Lymphocyte 5'-nucleotidase activity as a marker of B-cell maturation and immunoglobulin synthesis. Clin Res 27:321 A, 1979

62. Quagliata F, Faig D, Conklyn M, et al: Studies on the lymphocyte 5 -nucleotidase in chronic lymphocyte leukemia, infectious mononucleosis, normal subpopulations, and phytohemagglutinin-stimulated cells. Cancer Res 34:3197-3202, 1974

63. Lopes J, Zucker-Franklin D, Silber R: Heterogeneity of 5 -nucleotidase activity in lymphocytes in chronic lymphocytic leukemia. J Clin Invest 52:1297-1300, 1973

64. LaMantia K, Conklyn M, Quagliata F, et al: Lymphocyte 5 -nucleotidase absence of detectable protein in chronic lymphocytic leukemia. Blood 50:683-689, 1977

65. Reaman GH, Levin N, Muchmore A, et al: Diminished lymphoblast $5^{\prime}$-nucleotidase activity in acute lymphoblastic leukemia with T-cell characteristics. N Engl J Med 300:1374-1377, 1979

66. Giblett ER, Anderson JE, Cohen F, et al: Adenosinedeaminase deficiency in two patients with severely impaired cellular immunity. Lancet 2:1067-1069, 1972

67. Meuwissen HJ, pickering RJ, Pollara B, et al: Combined Immunodeficiency and Adenosine Deaminase Deficiency: A Molecular Defect. New York, Academic Press Inc., 1975

68. Hirschhorn R: Clinical delineation of adenosine deaminase deficiency In Enzyme Defects and Immune Dysfunction. Ciba Foundation Symposium No. 68, Amsterdam, Elsevier, 1979, pp 35-49

69. Schwartz AL, Polmar SH, Stern RC, et al: Abnormal platelet aggregation in severe combined immunodeficiency disease with adenosine deaminase deficiency. Br J Haematol 39:189-194, 1978

70. Lee $\mathrm{CH}$, Evans SP, Rozenberg MD, et al: In vitro platelet abnormality in adenosine deaminase deficiency and severe combined immunodeficiency. Blood 53:465-471, 1979

71. Hirschhorn R, Papageorgiou PS, Kesarwala HH, et al: Amelioration of neurologic abnormalities after enzyme replacement in adenosine deaminase deficiency. New Engl J Med 303:377 380, 1980

72. Coleman MS, Donofrio J, Hutton JJ, et al: Abnormal concentrations of deoxynucleotides in adenosine-deaminase (ADA) deficiency and severe combined immunodeficiency disease (SCID). Blood 50:292, 1977

73. Cohen H, Hirschhorn R, Horowitz S, et al: Deoxyadenosine triphosphate as a potentially toxic metabolite in adenosine deaminase deficiency. Proc Natl Acad Sci USA 75:472-476, 1978

74. Simmonds HA, Panayi GS, Corrigall V: A role for purine metabolism in the immune response: Adenosine deaminase activity and deoxyadenosine catabolism. Lancet 1:60-63, 1978

75. Donofrio J, Coleman MS, Hutton JJ, et al: Overproduction of adenine deoxynucleoside and deoxynucleotides in adenosine deaminase deficiency with severe combined immunodeficiency disease. J Clin Invest 62:884-887, 1978 
76. Mills GL, Goldblum RM, Newkirk KE, et al: Urinary excretion of purines, purine nucleoside and pseudouridine in adenosine deaminase deficiency. Biochem Med 20:180-199, 1978

77. Schmalstieg FC, Nelson JA, Mills GC, et al: Increased purine nucleotides in adenosine-deaminase deficient lymphocytes. $J$ Pediatr 91:48-51, 1977

78. Hershfield MS, Kredich NM, Ownby DR, et al: In vivo inactivation of erythrocyte $S$-adenosylhomocysteine hydrolase by 2 '-deoxyadenosine in adenosine deaminase-deficient patients. J Clin Invest 63:807-811, 1979

79. Kaminska J, Fox IH: Decreased S-adenosylhomocysteine hydrolase in inborn errors of purine metabolism. J Lab Clin Med 96:141-147, 1980

80. Van der Weyden MB, Buckley RH, Kelley WN: Molecular form of adenosine deaminase in severe combined immunodeficiency. Biochem Biophys Res Commun 57:590-595, 1974

81. Chen S, Scott RC, Swedberg RK: Heterogeneity for adenosine deaminase deficiency; expression of the enzyme in cultured skin fibroblasts and amniotic fluid cells. Am J Human Genet 27:46-52 1975

82. Hirschhorn R, Beratis N, Rosen FS: Characterization of residual enzyme activity in fibroblasts from patients with adenosine deaminase deficiency and combined immunodeficiency: Evidence for a mutant enzyme. Proc Natl Acad Sci 73:213-217, 1976

83. Schrader WP, Pollara B, Meuwissen HJ: Characterization of the residual adenosine deaminating activity in the spleen of a patient with combined immunodeficiency disease and adenosine deaminase deficiency. Proc Natl Acad Sci USA 75:446-450, 1978

84 Carson DA, Goldblum R, Keightley R, et al: Immunochemical analysis of adenosine deaminase in combined immunodeficiency disease. Adv Exp Med Biol 76A:463-470, 1977

85. Daddona PE, Frohman MA, Kelley WN: Radioimmunochemical quantitation of adenosine deaminase. J Clin Invest 64:798-803, 1979

86. Jenkins T, Lane AB, Nurse GT, et al: Red cell adenosine deaminase (ADA) polymorphism in Southern Africa, with special reference to ADA deficiency among the ! Kung. Ann Hum Genet, Lond. 42:425-433, 1979

87. Hirschhorn R, Roegner V, Jenkins $T$, et al: Erythrocyte adenosine deaminase deficiency without immunodeficiency. Evidence for an unstable mutant enzyme. J Clin Invest 64:1130-1139, 1979

88. Polmar SH, Stern RC, Schwartz AL, et al: Enzyme replacement therapy for adenosine deaminase deficiency and severe combined immunodeficiency. N Engl J Med 295:1137-1143, 1976

89. Polmar SH: Enzyme replacement and other biochemical approaches to therapy of adenosine deaminase deficiency, in: Enzyme Defects and Immune Dysfunction, Ciba Foundation Symposium No 68. Amsterdam. Elsevier Press, 1979, pp 213-223

90. Hirschhorn R, Roegner $V$, Rubinstein A, et al: Plasma deoxyadenosine, adenosine and erythrocyte dATP are elevated at birth in an adenosine deaminase-deficient child. J Clin Invest 65:768-771, 1980

91. Hirschhorn R, Papageorgiou P, Rubinstein A, et al: Transfusion vs. bone marrow transplantation in combined immunodeficiency. Clin Res 27:507A, 1979

92. Parkman R, Gelfand EW, Rosen FS, et al: Severe combined immunodeficiency and adenosine deaminase deficiency. $N$ Engl $J$ Med 292:714-719,1975

93. Chen S, Ochs HD, Scott CR, et al: Adenosine deaminase deficiency disappearance of adenosine deoxynucleotides from a patient's erythrocytes after successful marrow transplantation. J Clin Invest 62:1386-1389, 1978

94. Rubinstein A, Hirschhorn R, Sicklick $M$, ef al: In vivo and in vitro effects of thymosin and adenosine deaminase on adenosinedeaminase-deficient lymphocytes. N Engl J Med 300:387-392, 1979

95. Fox IH. Kelley WN: The role of adenosine and deoxyadenosine in mammalian cells. Ann Rev Biochem 47:655-686, 1978

96. Mitchell BS, Mejias E, Daddona PE, et al: Purinogenic immunodeficiency diseases: Selective toxicity of deoxyribonucleosides for T-cells. Proc Natl Acad Sci USA 75:5011-5014, 1978

97. Gudas LJ. Ullman B, Cohen A, et al: Deoxyguanosine toxicity in a mouse T-lymphoma: Relationship to purine nucleoside phosphorylase-associated immune dysfunction. Cell 14:531-538, 1978

98. Chan T: Deoxyguanosine toxicity on lymphoid cells as a cause for immunosuppression in purine nucleoside phosphorylase deficiency. Cell 14:523-530, 1978

99. Carson DA, Kaye J, Seegmiller JE: Differential sensitivity of human leukemic T-cell lines and B-cell lines to growth inhibition by deoxyadenosine. J Immunol 121:1726-1731, 1978

100. Gelfand EW, Lee JI, Dosch H-M: Selective toxicity of purine deoxynucleosides for human lymphocyte growth and function. Proc Natl Acad Sci USA 76:1998-2002, 1979

101. Wortmann RL, Mitchell BS, Edwards NL, et al: Biochemical basis for differential deoxyadenosine toxicity to $T$ - and Blymphoblasts: A role for 5'-nucleotidase. Proc Natl Acad Sci USA 76:2434-2437, 1979

102. Carson DA, Kaye J, Matsumoto S, et al: Biochemical basis for enhanced toxicity of deoxyribonucleosides toward malignant human T cell lines. Proc Natl Acad Sci USA 76:2430-2433, 1979

103. Fdwards NI, Mond JJ, Mitchell BS, et al: Deoxyribonucleotide triphosphate accumulation and purine activity in murine lymphocytes support for a model of selective lymphocyte toxicity. Clin Res 29:140A, 1979

104. Allan D. Crumpton MS: Isolation and composition of human thymocyte plasma membrane. Biochim Biophys Acta 274:22-27, 1972

105. Uusitalo RJ, Karnovsky MJ: Surface localization 5'-nucleotidase on the mouse lymphocyte. J Hist Cytochem 25:87-96, 1977

106. Uusitalo RJ, Karnovsky MJ: 5'-nucleotidase in different populations of mouse lymphocyte. J Hist Cytochem 25:97-103, 1977

107. Ullman B, Gudas LJ, Clift SM, et al: Isolation and characterization of purine-nucleoside phosphorylase-deficient T-lymphoma cells and secondary mutants with altered ribonucleotide reductase: genetic model for immunodeficiency disease. Proc Natl Acad Sci USA 76:1074-1078, 1979

108. Fox IH, Kaminska J, Wortmann RL, et at: Deoxyadenosine inhibits DNA synthesis in cultured human fibroblasts. J Lab Clin Med 94:52-59, 1979

109. Wilson JM, Mitchell BS, Kelley WN: Molecular mechanisms of deoxynucleoside toxicity in T-lymphoblasts. $J$ Clin Invest 64:1475-1484, 1979

110. Salvatore F. Borek E, Zapia V, et al: The Biochemistry of S-adenosylmethionine. New York: Columbia University Press, 1977, p 557

111. Kredich NM, Martin DW Jr: Role of S-adenosylhomocysteine in adenosine-mediated toxicity in cultured mouse $\mathrm{T}$ lymphoma cells. Cell 12:931-938, 1977

112. Kredich MN, Hershfield MS: S-adenosylhomocysteine toxicity in normal and adenosine kinase-deficient lymphoblasts of human origin. Proc Natl Acad Sci USA 76:2450-2454, 1979

113. Pike MC, Kredich MN, Snyderman R: Requirement of $\mathrm{S}$-adenosyl-L-methionine-mediated methylation for human monocyte chemotaxis. Proc Natl Acad Sci USA 75:3928-3932, 1978

114. Hershfield MS: Apparent suicide inactivation of human 
lymphoblast S-adenosylhomocysteine hydrolase by 2'-deoxyadenosine and adenine arabinoside. J Biol Chem 254:22-25, 1979

115. Hirata F, Axelrod J: Phospholipid methylation and biological signal transmission. Science 209:1082-1090, 1980

116. Palella TD, Schatz RA, Kaminska JB, et al: Homocysteine dependent nucleoside toxicity in cultured $\mathrm{T}$ - and B-lymphoblasts. Clin Res 28:143A, 1980

117. Wolberg G, Zimmerman TP, Hiemstra $K$, et al: Adenosine inhibition of lymphocyte-mediated cytolysis: Possible role of cyclic adenosine monophosphate. Science 187:957-959, 1975

118. Zenser TV: Formation of adenosine- $3^{\prime}, 5^{\prime}$-monophosphate from adenosine in mouse thymocytes. Biochim Biophys Acta 404:212-213, 1975

119. Zimmerman TP, Rideout JL, Wolberg G, et al: 2-Fluoroadenosine 3', 5'-monophosphate: A metabolite of 2-fiuoroadenosine in mouse cytotoxic lymphocytes J Biol Chem 251:6757-6766, 1976

120. Marone G, Plaut M, Lichtenstein LM: Characterization of a specific adenosine receptor on human lymphocytes. J Immunol 11:2153-2159, 1978

121. Bourne HR, Lichtenstein LM, Melmon KL, et al: Modulation of inflammation and immunity by cyclic AMP. Science 184:1928,1974

122. Giblett ER, Ammann AJ, Wara DW, et al: Nucleosidephosphorylase deficiency in a child with severely defective T-cell immunity and normal B-cell immunity. Lancet 1:1010-1013, 1975

123. Gelfand EW, Dosch H, Biggar WD, et al: Partial purine nucleoside phosphorylasc deficiency: Studies of lymphocyte function. J Clin Invest 61:1071-1080, 1978

124. Rich KC, Arnold WJ, Palella T, et al: Cellular immune deficiency with autoimmune hemolytic anemia in purine nucleoside phosphorylase deficiency. Am J Med 67:172-176, 1979

125. Luca EC, Aiuti F, Lucarelli $P$, et al: $\wedge$ patient with nucleoside phosphorylase deficiency, selective $\mathrm{T}$-cell deficiency and autoimmune hemolytic anemia. J Pediatr 93:1000-1003, 1978

126. Cohen A, Doyle D, Martin DW Jr., et al: Abnormal purine metabolism and purine overproduction in a patient deficient in purine nucleoside phosphorylase. N Engl J Med 295:1449-1454, 1976

127. Siegenbeek Van Heukelom LH, Akkerman JWN, Staal GEJ, et al: A patient with purine nucleoside phosphorylase deficiency: Enzymological and metabolic aspects. Clin Chim Acta 74:271279,1977

128. Fox $1 \mathrm{H}$, Kelley WN: Phosphoribosylpyrophosphate in man: Biochemical and clinical significance. Ann Int Med 74:424-433, 1971

129. Cohen A, Gudas LJ, Ammann AJ, et al: Deoxyguanosine triphosphate as a possible toxic metabolite associated with purine nucleoside phosphorylase deficiency. J Clin Invest 61:1405-1409, 1978

130. Wortmann RL, Andres CM, Kaminska J, et al: Purine nucleoside phosphorylase deficiency: Biochemical properties and heterogeneity in two families. Arth Rheum 22:524-531, 1979

131. Fox IH, Andres CM, Gelfand EW, et al: Purine nucleoside phosphorylase deficiency: Altered kinetic properties of a mutant enzyme. Science 197:1084-1088, 1977

132. Osbourne WRA, Chen S, Giblett ER, et al: Purine nucleoside phosphorylase deficiency: Evidence for molecular heterogeneity in two families with enzyme-deficient members. J Clin Invest 60:741-746, 1977

133. Gudas LJ, Zannis VI, Clift SM, et al: Characterization of mutant subunits of human purine nucleoside phosphorylase. J Biol Chem 253:8916-8924, 1978

134. Fox IH, Andres CM, Kaminska J, et al: Purine nucleoside phosphorylase, in: Enzyme Defects and Immune Dysfunction, Ciba Foundation Symposium No. 68, 1979, pp 193-202
135. Rich KC, Mejias E, Fox IH: Nucleoside phosphorylase deficiency: Improved immune function with enzyme replacement therapy. New Engl J Med 303:973-977, 1980

136. Zegers BJM, Stoop JW, Staal GEJ, et al: An approach to the restoration of $T$ cell function in a purine nucleoside phosphorylase deficient patient, In Enzyme Defects and Immune Dysfunction, Ciba Foundation Symposium No. 68, Amsterdam, Elsevier Press, 1979. pp 231-247

137. Ammann AJ: Immunological aberrations in purine nucleotide phosphorylase deficiencies, In Enzyme Defects and Immune Dysfunction, Ciba Foundation Symposium No. 68, New York, Excerpta Medicus, 1979, pp 55-69

138. Ochs UH, Chen S, Ochs HD, et al: Purine nucleoside phosphorylase deficiency: a molecular model for selective loss of T cell function. J Immunol 122:2424-2429, 1979

139. Fishbein WN, Armbrustmacher VW, Griffin JL: Myoadenylate deaminase deficiency: A new disease of muscle. Science 200:545-548, 1978

140. Fishbein WN, Griffin JL, Nagarajan K, et al: Immunologic uniqueness of muscle adenylate deaminase (MAD) and genetic transmission of the deficiency state. Clin Res 27:274A, 1979

141. Fishbein WN, Armbrustmacher VM, Griffin JL: Skeletal muscle adenylate deaminase, adenylate kinase, and creatine kinase in myoadenylate deaminase deficiency and malignant hyperthermia. Clin Res 28:288A, 1980

142. Shumate JB, Katnik R, Ruiz M, et al: Myoadenylate deaminase deficiency. Muscle and Nerve 2:213 216, 1979

143. Fishbein WN, Griffin JL, Nagarajan K, et al: Myoadenylate deaminase deficiency: Association with collagen disease. Clin Res 27:37A, 1979

144. Sabina RL, Swain JL, Patten BM, et al: Disruption of the purine nucleotide cycle: A potential explanation for muscle dysfunction in myoadenylate deaminase deficiency. J Clin Invest 66:1419. 1423,1980

145. Wyngaarden JB: Hereditary Xanthinuria, in Stanbury JB, Wyngaarden JB, Fredrickson DS (eds): The Metabolic Basis of Inherited Disease, New York, McGraw-Hill Book Co., 1978, pp 1037-1044

146. Kumar S, Ou S, Rathi M: Deficiency of guanine deaminase in human brain: a new brain disorder? N Engl J Med 300:13321333, 1979

147. Marcolongo R, Marinello E, Pompucci G, et al: The role of xanthine oxidase in hyperuricemic states. Arthritis Rheum 17:430 438,1974

148. Carcassi A: Xanthine oxidase activity in a gouty patient with a partial deficiency of HGPRT. Adv Exp Med Biol 76A:346350,1977

149. Wyngaarden JB, Kelley WN: Gout and Hyperuricemia. New York, Grune and Stratton, 1976, pp 309-344

150. Debray H, Cartier P, Temstet A, et al: Child's urinary lithiasis revealing a complete deficit in adenine phosphoribosyltransferase. Ped Res 10:762-776, 1976

151. Van Acker KJ, Simmonds HA, Potter C, et al: Complete deficiency of adenine phosphoribosyltransferase: report of a family N Engl J Med 297:127-1 32, 1977

152. Fox IH, Lacroix S, Planet G, et al: Partial deficiency of adenine phosphoribosyltransferase in man. Medicine 56:515-526, 1977

153. Wyngaarden JB, Kelley WN: Gout, in Stanbury JB, Wyngaarden JB, Frederickson DS (eds): The Metabolic Basis of Inherited Disease, New York, McGraw-Hill Book Co., 1978, pp 916-1010

154. Becker MA, Yen RCK, Itkin P, et al: Regional localization of the gene for human phosphoribosylpyrophosphate synthetase on the X chromosome. Science 203:1016-1019, 1979 
155. Farber E: ATP and cell integrity. Fed Proc 32:1534-1539, 1973

156. Reibel DK, Rovetto MJ: Myocardial ATP synthesis and mechanical function following oxygen deficiency. Am J Physinl 234:H62-H64, 1978

157. Darsee JR, Nutter DO: Reversible severe congestive cardiomyopathy in three cases of hypophosphatemia. Ann Int Med 89:867-870, 1978

158. O'Connor LR, Wheeler WS, Bethune JF: Effect of hypophosphatemia on myocardial performance in man. N Engl J Med 297:901-903, 1977

159. Fuller TJ, Nichols WW, Brenner BJ, et al: Reversible depression in myocardial performance in dogs with experimental phosphorus deficiency. J Clin Invest 62:1194-1200, 1978

160. Knochel JP, Barcenas C, Cotton JR, et al: Hypophosphatemia and rhabdomyolysis. J Clin Invest 62:1240-1246, 1978

161. Jennings RB, Hawkins HK, Lowe JE, et al: Relation between high energy phosphate and lethal injury in myocardial ischemia in the dog. Am J Pathol 92:187-207, 1978

162. Morgan HE: The cellular basis of ischemia and infarction. Circulation 53:143, 1976

163. Kelley WN, Rosenbloom FM, Seegmiller JE, et al: Excessive production of uric acid in type I glycogen storage disease. J Pediatr 72:488-496, 1968

164. Alepa FP, Howell RR, Klinenberg JR, et al: Relationships between glycogen storage disease and tophaceous gout. Am J Med 42:58-66, 1967

165. Greene HL, Wilson FA, Hefferan P, et al: Continuous nocturnal intragastric feeding for management of Type I glycogenstorage disease. N Engl J Med 294:423-425, 1976

166. Roe TF, Kogut MD: The pathogenesis of hyperuricemia in glycogen storage disease, type I. Pediatr Res 11:664-669, 1977

167. Greene HL, Wilson FA, Hefferan P, et al: ATP depletion, a possible role in the pathogenesis of hyperuricemia in glycogen storage disease type I. J Clin Invest 62:321-328, 1978

168. Froesch ER: Essential fructosuria and hereditary fructose intolerance, in Stanbury JB, Wyngaarden JB, Fredrickson DS (eds): The Metabolic Basis of Inherited Disease, (ed 4), New York, McGraw-Hill Book Co., 1978, pp 121-136

169. Berne RM: Cardiac nucleotides in hypoxia: Possible role in regulation of coronary blood flow. Am J Physiol 204:317-322, 1963

170. Imai S, Riley AL, Berne RM: Effect of ischemia on adenine nucleotides in cardiac and skeletal muscle. Circulat Res 15:443450,1964

171. Opie LH, Thomas M, Owen P, et al: Increased coronary venous inorganic phosphate concentrations during experimental myocardial ischemia. Am J Cardiol 30:503-513, 1972

172. Gudbjarnason S, Ravens KG, Mathes P: Metabolic changes in infarcted and non-infarcted myocardium during the postinfarction period, in Bajusz E, Rona G (eds): Recent Advances in Studies on Cardiac Structure and Metabolism, vol 1, Baltimore, Park Press. 1972

173. Parker JC, Jones CE, Thomas JX, Jr: Effect of ischemia and infarction on regional content of adenine nucleotides and derivatives in canine left ventricle. Cardiology 61:279-288, 1976

174. Remme WJ, DeJong JW, Verdouw PD: Effects of pacing induced myocardial ischemia on hypoxanthine efflux from the human heart. Am J Cardiol 40:55-62, 1977

175. Fox $\Lambda \mathrm{C}$, Reed GE, Glassman $E$, et al: Release of adenosine from human hearts during angina induced by rapid atrial pacing. $J$ Clin Invest 53:1447-1457, 1974

176. Fox AC, Reed GE, Meilman H, et al: Release of nucleosides from canine and human hearts as an index of prior ischemia. Am $J$ Cardiol 43:52-58, 1979

177. Cowsert MK Jr, Carrier O Jr, Crowell JW: The effect of hemorrhagic shock on blood uric acid level. Can J Physiol Pharmacol 44:86I-864, 1966

178. Chaudrey IH, Sayeed MM, Baue AE: Effect of hemorrhagic shock on tissue adenine nucleotides in conscious rats. Can J Physiol Pharmacol 52:131-137, 1974

179. Saugstad OD, Ostrem T: Hypoxanthine levels of plasma during hypoxemia in dogs. Eur Surg Res 9:23-33, 1977

180. Saugstad OD, Ostrem T: Hypoxanthine and urate levels of plasma during and after hemorrhagic hypotension in dogs. Europ Surg Res 9:48-56, 1977

181. Chaudrey IH, Sayeed MM, Baue AE: Degradation of adenine nucleotides by the soleus muscle in hemorrhagic shock. Surgery $77: 180-185,1975$

182. Cunningham SK, Keaveny TV: Splanchic argan adenine nucleotides and their metabolites in haemorrhagic shock. Irish $\mathbf{J}$ Med Sci 146:136-143, 1977

183. Chaudrey IH, Sayeed MM, Baue AE: Differences in the altered energy metabolism of hemorrhagic shock and hypoxemia. Can J Physiol Pharmacol 54:750-756, 1976

184. Chaudrey IH, Sayeed MM, Baue AE: Alterations in highenergy phosphates in hemorrhagic shock as related to tissue and organ function. Surgery 79:666-668, 1976

185. Simeone FA, Abraham J, Hopkins RW, et al: Levels of allantoin and uric acid in dogs subjected to hemorrhagic shock. $J$ Surg Res 19:373-380, 1975

186. Pontegnie-Istace S, Lambotte L: Liver adenine nucleotide metabolism during hypothermic anoxia and a recovery period in perfusion. J Surg Res 23:339-347, 1977

187. Osswald H, Schmitz H-J, Kemper R: Tissue content of adenosine, inosine and hypoxanthine in the rat kidney after ischemia and postischemic recirculation. Pflugers Arch 371:45-49, 1977

188. Buhl MR, Kemp G, Kemp E: Hypoxanthine excretion during preservation of rabbit kidneys for transplantation. Transplantation 21:460-467, 1976

189. Buhl MR: Oxypurine excretion during preservation: An indicator of ischemic damage. Scand J Clin Lab Invest 36:164-174, 1976

190. Buhl MR: The postanoxic regeneration of $5^{\prime}$-adenine nucleotides in rabbit kidney tissue during in vitro perfusion. Scand $\mathrm{J}$ Clin Lab Invest 36:175-181, 1976

191. Kampa IS, Frascella DW: Blood uric acid levels during hyperthermic stress. Life Sciences 20:1373-1376, 1977

192. Saugstad OD, Kroese A, Myhre HD: Alteration of plasma hypoxanthine concentration during ischemia in the forelimb of the pig. Scand J Clin Lab Invest 37:517-520, 1977

193. Schultz V, Lowenstein JM: The purine nucleotide cycle: Studies of ammonia production and interconversions of adenine and hypoxanthine nucleotides and nucleosides by rat brain in situ. J Biol Chem 253:1938-1943, 1978

194. Weiner K: Uraemia and hyperuricaemia in acute myocardial infarction. Clin Chim Acta 73:45-50, 1976

195. Ghosh P, Cochrane AMG, Gordon PWN, et al: Changes in plasma urate concentration immediately after acute myocardial infarction. Brit Med J 4:261-262, 1975

196. Rizzon P, Human GP, Snyman HW: Incidence, pattern and mechanism of transient hyperuricemia in patients with acute myocardial infarction. Mal Cardiovasc 9:423-439, 1968

197. Dosman JA, Crawhall JC, Klassen GA: Uric acid kinetic studies in the immediate post-myocardial-infarction period. Metabolism 24:473-480, 1975

198. Weil MH, Shubin H: Diagnosis and Treatment of Shock. Baltimore, Williams and Wilkins, 1967, p 268

199. Bergeaux G, Klein RC: Hyperuricemia following smoke inhalation. Am Rev Res Dis 109:145-147, 1974 
200. Isomaki H, Kreus K-E: Serum and urinary uric acid in respiratory acidosis. Acta Med Scand 184:293-296, 1968

201. Valat JP, Lamisse F, LeChavallier PL, et al: Les variations de l'uricemie au cours des compensations respirtoires aigues des bronchopathies chroniques. ${ }^{*}$ Revue de Pheumat 41:179-184, 1974

202. Raivio KO: Neonatal hyperuricemia. J Pediatr 88:625-630, 1976

203. Saugstad OD: Hypoxanthine as a measurement of hypoxia. Pediatr Res 9:158-161, 1975

204. Meberg A, Saugstad OD: Hypoxanthine in cerebrospinal fluid in children. Scand J Clin Lab Invest 38:437-440, 1978

205. Manzke H, Dorner K, Grunitz J: Urinary hypoxanthine, xanthine and uric acid excretion in newborn infants with perinatal complications. Acta Pediatr Scand 66:713-717, 1977

206. Manzke H, Eigster G, Harms D, et al: Uric acid infarctions in the kidneys of newborn infants: A study on the changing incidence and on oxypurine ratios. Eur J Pediatr 126:29-35, 1977

207. Epstein SE, Goldstein RE, Redwood DR, et al: The early phase of acute myocardial infarction: Pharmacologic aspects of therapy. Ann Int Med 78:918-936, 1973

208. Hillis LD, Braunwald E: Myocardial ischemia (second of three parts). N Engl J Med 296:1034-1041, 1977

209. Majid PA, Sharma B, Meeran MKM, et al: Insulin and glucose in the treatment of heart failure. Lancet 2:937-941, 1972

210. Kingaby RD, Lab MJ, Woollard KJ: Restoration of function in ischaemic myocardium by inosine. J Physiol 272:102-103, 1977

211. Fernando AR, Griffiths Jr, O'Donoghue EPN, et al: Enhanced preservation of the ischaemic kidney with inosine. Iancet 1:555-558, 1976

212. Hirasawa H, Chaudry IH, Baue AE: Improved hepatic function and survival with adenosine triphosphate-magnesium chloride after hepatic ischemia. Surg 83:655-662, 1978

213. Edwards NI, Recker D, Fox IH: Decreased purine excretion during allopurinal therapy: Contribution by enhanced purine salvage. Clin Res 28:785A, 1980

214. Fox IH, Wyngaarden JB, Kelley WN: Depletion of erythrocyte phosphoribosylpyrophosphate in man: A newly observed effect of allopurinol. N Engl J Med 283:1177-1182, 1970

215. Elion $G B, Y u T F$, Gutman AB, et al: Renal clearance of oxypurinol, the chief metabolite of allopurinol. Am J Med 45:69-77, 1968

216. Beardmore TD, Kelley WN: Mechanism of allopurinolmediated inhibition of pyrimidine biosynthesis. J Lab Clin Med 78:696-704, 1971

217. Kmetec E, Mendoza AR, Stanley EL: Effects of allopurinol on purine metabolism in cultured heart cells. Biochem Pharmacol 27:1298-1300, 1978

218. Mentz $P$, Forster $W$ : The effect of allopurinol upon isolated heart preparations on the guinea pig. Acta Biol Med Germ 33:463 466,1974

219. Vasko KA, DeWall RA, Kedzi P: Effects of allopurinol on the ischemic myocardium. Ped Proc 29:797A, 1970
220. Crowell JW, Jones CE, Smith EE: Effect of allopurinol on hemorrhagic shock. Am J Physiol 216:744-748, 1969

221. Henson EC, Lockhard VG, Crowell JW, et al: Recovery from a usually lethal period of hypotension. Arch Pathol 95:73-80. 1973

222. Baker $\mathrm{CH}$ : Protection against irreversible hemorrhagic shock by allopurinol. Proc Soc Exp Biol Med 141:694-698, 1972

223. Toledo-Pereyra LH, Simmons RL, Najarian JS: Effect of allopurinol on the preservation of ischemic kidneys perfused with plasma or plasma substitutes. Ann Surg 180:78-82, 1974

224. Chattergee SN: Pharmacologic agents of potential value in protecting kidneys from ischemic damage. Transplt Proc 9:1579. 1582,1977

225. Toledo-Pereyra LH, Simmons RL, Najarian JS: Comparative effects of chlorpromazine, methylprednisolone, and allopurinol during small bowel preservation. Am J Surg 126:631-634, 1973

226. Hopkins RW, Abraham J, Simeone FA, et al: Effects of allopurinol on hepatic adenosine nucleotides in hemorrhagic shock. J Surg Res 19:381-390, 1975

227. Shatney $\mathrm{CH}$, MacCarter DJ, Lillehei RC: Effects of allopurinol, propranolol and methylprednisolone on infarct size in experimental myocardial infarction. Am J Cardiol 37:572-579, 1976

228. Paine RM, Smyth JF, Harrup KR: Biochemical consequences of treatment with adenosine deaminase inhibitor 2'-deoxycoformycin. Adv Exp Med Biol 122B:365-371, 1980

229. Mitchell BS, Koller CA, Heyn R: Inhibition of adenosine deaminase activity results in cytotoxicity in $\mathrm{T}$ lymphoblasts in vivo. Blood 56:556-559, 1980

230. Yu AL, Kung RH, Bakay B, et al: In vitro and in vivo effect of deoxycoformycin in human $\mathrm{T}$ cell leukemia. Adv Exp Med Biol 122B:373-379, 1980

231. Koller CA, Mitchell BS, Grever MR, et al: Treatment of acute lymphoblastic leukemia with 2'-deoxycoformycin: clinical and biochemical consequences of adenosine deaminase inhibition. Cancer Treat Rep 64:1949-1952, 1980

232. Yun S, Suelter CH: Human erythrocyte 5'-AMP aminohydrolase. J Biol Chem 253:404-408, 1978

233. Spector $T$, Miller RL: Mammalian adenylosuccinate synthetase: Nucleotide monophosphate substrates and inhibitors. Biochim Biophys Acta 445:509-517, 1976

234. Spector T: Mammalian adenylosuccinate lyase: Participation in the conversion of $2^{\prime}$-dIMP and B-D-arabinosyl-IMP to adenine nucleotides. Biochim Biophy Acta 481:741-745, 1977

235. Miller RL, Adamczyk DL: Inosine 5'-monophosphate dehydrogenase from sarcoma 180 cells-substrate and inhibitor specificity. Biochem Pharmacol 25:883-888, 1976

236. Spector T: Studies with GMP synthetase from Ehrlich ascites tumor cells: Purification properties and interaction with nucleotide analogs. J Biol Chem 250:7372-7376, 1975

237. Spector T, Jones TE, Miller RL: Reaction mechanism and specificity of human GMP reductase: Substrates, inhibitors, activators, and inactivators. J Biol Chem 254:2308-2315, 1979 